\title{
Advective Transport of Interacting Solutes: The Chromatographic Model
}

\author{
Joachim Gruber
}

Affiliation at the time this was first published:

Arbeitsbereich Umweltschutztechnik, TU Harburg, Germany

E-Mail: Joachim.Gruber@acamedia.info

\begin{abstract}
Species on porous media surfaces exposed to aqueous solutions can still not yet be determined unambiguously. The influence of these ambiguities on contaminant transport needs to be understood. Here methods of multicomponent chromatography are presented that allow to visualize the effects of the ambiguities. The Riemann problem is solved to a large extent based on the mathematics of non-linear hyperbolic differential equations, before the problem is handed over to the computer. Since thereby the computational efforts are kept compatible with the corresponding limitations in a chemical laboratory, this method has been used for decades in chemical engineering. The method is illustrated for various multicomponent isotherms, e.g. the one underlying surface complexation models as implemented in the MINEQL family of programs.
\end{abstract}

\section{Introduction}

Methods to determine the surface species on porous media in contact with aqueous solutions have been improved for more than three decades. But still our understanding of the surface chemical processes is based on models the applicability of which we cannot predict (Lützenkirchen 2012, Payne et al. 2013). This is of particular concern when it comes to assessing the long-term safety of high-level radioactive waste repositories: We need to evaluate how our lack of understanding will affect our predictions of contaminant migration. 
Two principally different paths have been taken to predict contaminant migration. On both paths transport equations governing contaminant migration are solved. Path 1 uses numerical solution techniques for equations that represent our understanding of the processes as closely as reasonably achievable. Path 2 uses analytical, i.e. mathematical, solutions of simplified versions of the transport equations that we think represent general migration features.

\section{Path 1}

Affordable computers have become capable of numerically calculating transport of several chemically and biologically interacting components in porous media. Examples of such components are natural ions, ligands, nutrients and contaminants. Many transport codes have been written, as is evident from reviews (e.g. Kirkner and Reeves, 1988; Reeves and Kirkner, 1988; Kinzelbach et al., 1989). Numerical difficulties and long computation times have been addressed in various ways, depending on the choice of the geochemical problem. Subroutines, e.g. PHREEQE, MINEQL or other members of the MINEQL family, such as MINTEQ, GEOCHEM or HYDROQL, are called at each time step to establish chemical equilibrium in all nodes (Walsh et al., 1984; Cederberg et al., 1985; Novak et al., 1988; Berninger et al., 1991). When applied to the nodes sequentially, these subroutines need more than $90 \%$ of the computation time. Soon excessive time is spent in these subroutines when the number of nodes is increased, unless the computer code has been vectorized, thus being able to establish chemical equilibrium in all nodes at once (Vogt, 1990).

Path 2

Lichtner (1992) and Ortoleva and coworkers (1987) went in another direction, avoiding super- or mini-supercomputers by introducing very potent approximations in the transport equations for the case of mineral precipitation and dissolution.

This paper will deal with the visualization of the 1-dimensional migration of chemically interacting water constituents disregarding diffusion and dispersion. Here path 2 uses the mathematics of nonlinear sets of hyperbolic partial differential equations in one space coordinate and time (Lax, 1973) and multicomponent chromatography (Helfferich and Klein, 1970; Rhee et al., 1989). Both, mathematics and chromatography provide tools that help us understand and design numerical calculations as well as experiments when transport is purely advective and dominated by adsorption. The procedure to calculate the concentration profile is simpler and faster than with the above mentioned numerical models, largely because general 
properties of the solution of the problem are derived from mathematics rather than left to be found by the computer (Schweich et al., 1993). This way of proceeding has been used successfully in the field of chemical engineering (Helfferich, 1967; Hwang et al., 1988) and environmental sciences (Charbeneau, 1981, 1988; Bryant, 2000, Prigiobbe, 2012a, 2012b, 2013). The purpose of this paper is to demonstrate its potential in the latter field, i.e. to predict contaminant waves propagating through porous media.

After having introduced the transport equations (Sect. 2) and the concept of the centered waves (Sect. 3), this paper will

(1) present several solution techniques for hyperbolic differential equations, i.e.

analytical integration of the transport equations (Sect. 4),

the use of the coherence conditions (Sect. 5),

the use of the Jacobi matrix of the isotherms (Sect. 6),

and

(2) use this method to demonstrate the relationship that exists between the chemical interactions on the one hand -as represented by some adsorption isotherms and complex formation constants- and on the other hand the concentration profiles (Sect. 7). In this context, isotherms will be presented for

ligand exchange (Sect. 7.1.1),

surface bridge formation (Sect. 7.1.2),

adsorption on variable charge surfaces at low ionic strength (Sect. 7.1.3).

The properties of the waves in systems with some of these isotherms will be used to solve the system of transport equations by matrix inversion (Sect. 7.2), introducing a generalized chemical component, the Riemann invariant (Sect. 7.2.3).

(3) exemplify the presented analytical solutions with twocomponent systems (Sect. 8), because reliable adsorption data have been compiled mostly for such systems.

Chemists have been using speciation plots side by side with numerical speciation models to gain insight into the influence of complex formation constants in batch systems (see e.g. chapters $4.1-4.3$ in the textbook by Stumm and Morgan (1981)). Multicomponent 
chromatography provides us a similar graphical tool to help us understand the influence of thermodynamic constants on advective transport and to give us information we cannot get from a numerical transport model. This will be the topic of the second and third part of this paper.

\section{Transport Equations}

Migration of $\mathrm{N}_{0}$ chemical components $\mathrm{A}_{\mathrm{j}}\left(\mathrm{j}=1,2, \ldots, \mathrm{N}_{0}\right)$ in porous media is described by a set of $\mathrm{N}_{0}$ mass conservation laws. In the absence of precipitation or dissolution of solids the conservation laws have the form:

$\frac{\partial}{\partial t}\left\{\phi c_{j}(x, t)+C_{j}(x, t)\right\}+\frac{\partial}{\partial x}\left(v_{w}-D \frac{\partial}{\partial x}\right) c_{j}(x, t)=0 \quad\left(j=1, \ldots, N_{0}\right)$.

$c_{j}$ is the soluble and $C_{j}$ is the adsorbed concentration of component $A_{j}$. The constants $\phi \approx 0.3, \mathrm{v}_{\mathrm{w}} \leq 0.5 \mathrm{~m} / \mathrm{yr}$ and $\mathrm{D}=0.16\left(\mathrm{~m}^{2} / \mathrm{yr}\right) \tau+\delta \xi$ are the volumetric fraction of water, the flux of water and the hydrodynamic dispersion/diffusion coefficient of $\mathrm{A}_{\mathrm{j}}$ in the porous medium, respectively. $\tau(\approx 0.3)$ is the tortuosity, $\delta$ (units: $m$ ) is the dispersivity $(\approx \mathrm{L} / 100$, L (units: $\mathrm{m}$ ) being the length over which transport is calculated) and $\xi$ is the speed of the concentration $c_{j}$ (for definition of $\xi$ see (9) below).

The adsorbed concentration $C_{j}$ of component $A_{j}$ relaxes to the value $C_{j}{ }^{*}$, the so-called "isotherm", with a relaxation time $\varepsilon_{j}$ (first order kinetics)

$\frac{\partial}{\partial t} C_{j}(x, t)=\frac{1}{\varepsilon_{j}}\left\{C_{j}^{*}\left(c_{1}, c_{2}, \ldots, c_{N_{0}}\right)-C_{j}(x, t)\right\} \quad\left(j=1,2, \ldots, N_{0}\right)$

This paper will discuss concentrations profiles when the flux of water is typically $\mathrm{v}_{\mathrm{w}}<0.5 \mathrm{~m} / \mathrm{yr}$. Adsorption kinetics is then fast enough and has a negligible effect on the shape of the profile if $\varepsilon<1$ week (see appendices, 12 A. 1 and 2). Therefore $C_{j}=C_{j}^{*}$ will be assumed henceforth.

When also the diffusive term in (1) is neglected, the calculated concentration profiles will lack smoothness, but are expected to re- 
main unchanged otherwise. Because this research aims at finding trends caused by chemical interactions, the assumption $\mathrm{D}=0$ seems appropriate.

The resulting set of partial differential equations is hyperbolic and -due to the isotherm $\mathrm{C}_{\mathrm{j}}{ }^{*}\left(\mathrm{c}_{1}, \mathrm{c}_{2}, \ldots, \mathrm{c}_{\mathrm{No}}\right)$ - non-linear in the concentrations $c_{j}$.

$\frac{\partial}{\partial t}\left\{\phi c_{j}(x, t)+C_{j}^{*}\left(c_{1}, c_{2}, \ldots, c_{N_{0}}\right)\right\}+v_{w} \frac{\partial}{\partial x} c_{j}(x, t)=0 \quad\left(j=1,2, \ldots, N_{0}\right)$

Without giving the proofs, the next sections will present two basic phenomena in hyperbolic systems,

the centered wave, its representation in concentration space and its transport equation, and

the speed or retardation of the centered wave.

The first method presented below for finding solutions of the transport equations is connected with the equation defining the speed of a concentration. These definitions are called "coherence conditions" in chromatography. Three further solution methods will be presented thereafter.

\section{Riemann Problem and Centered Waves}

Solutions of (3) can be built from so-called "centered waves" (Helfferich and Klein, 1970).

There are two types of centered waves (Lax, 1973):

Rarefaction waves (called "diffuse waves" in chromatography). They meet the differential equations (3). This is the type that will mostly be dealt with here.

Shocks (called "self-sharpening waves" in chromatography). They meet the Rankine-Hugoniot relations (see (24) below), which are called "integral coherence conditions" in chromatography (Helfferich and Klein, 1970). 
Temple (1983) has shown that shocks and rarefaction waves coincide in two types of multicomponent systems with constant adsorption parameters and negligible soluble complexes: (1) when adsorption follows a multicomponent Langmuir isotherm (see (46) below) or (2) when adsorption can be described as an exchange process (see (41) below).

Centered waves are the solution of the Riemann problem, i.e. the response of the system (3) to a single abrupt change of the chemical composition of the incoming water ("feed") (from $\mathbf{c}_{+}$to $\mathbf{c}_{-}$). Let $\mathrm{x}=0$ be the initial location of this concentration jump, and assume that the pore water flows in positive $\mathrm{x}$-direction:

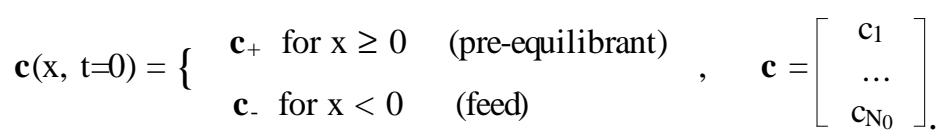

An example of centered waves in a two-component system (with components $\mathrm{M}$ and $\mathrm{H}$ ) is shown in figure 1 .

When there is no competition (figure 1a), $\mathrm{H}$ changes without $\mathrm{M}$ noticing it and vice versa. Thus each wave corresponds to a component. In figure $1 \mathrm{~b}, \mathrm{M}$ and $\mathrm{H}$ compete for adsorption sites, and the concentrations of both $\mathrm{M}$ and $\mathrm{H}$ change in both waves.

The general structure of the solution of the Riemann problem has been described and proved by Lax (1957): The discontinuity (4) develops into a sequence of constant states separated by centered waves (figure 2). The former are regions of fixed concentration. The heavy lines in figure 1 are the boundaries of the constant states. The concentration changes from $\mathbf{c}_{\mathrm{k}}$ to $\mathbf{c}_{\mathrm{k}+1}$ across the $\mathrm{k}$-wave, either continuously as shown in figure 2 for the 1-, 2 - and $\mathrm{N}_{0}$-waves, which are rarefaction waves, or abruptly as shown for the $\left(\mathrm{N}_{0}-1\right)$-wave, a shock. 


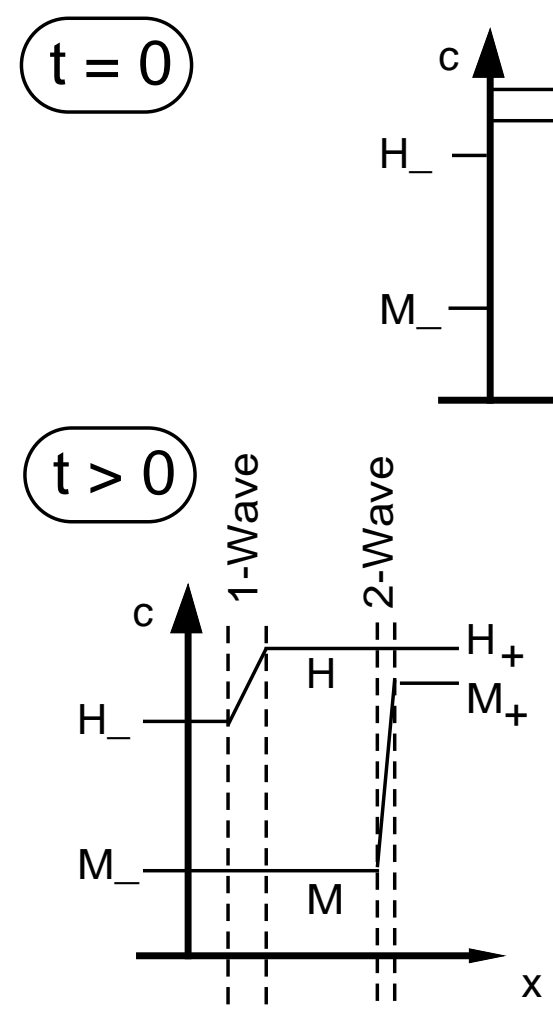

(a)

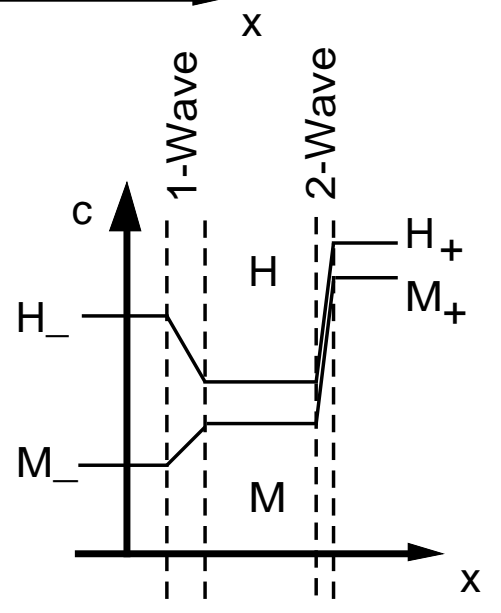

(b)

Fig. 1: Centered waves in a system with component $\mathrm{M}$ and $\mathrm{H}$ (a) without and (b) with competition between $\mathrm{M}$ and $\mathrm{H}$ for adsorption sites. The concentration jump $c_{-}=\left\{M_{-}, H_{-}\right\} \rightarrow C_{+}=\left\{M_{+}, H_{+}\right\}$at time $t=0$ develops into two waves.

Because all waves originate from the initial discontinuity at $\mathrm{x}=0$, for times $t>0$ the vector of concentrations $\mathbf{c}$ does not depend on $x$ and $t$ separately, but instead on the speed, the ratio $\xi=x / t$.

$$
\mathbf{c}(\mathrm{x}, \mathrm{t})=\mathbf{h}(\xi) \text {. }
$$

A concentration $\mathbf{c}(\mathrm{x}, \mathrm{t})=\mathbf{h}(\xi)$ is constant on the line $\mathrm{x} / \mathrm{t}=\xi$, the "characteristic" (light or heavy lines in figure 2). 


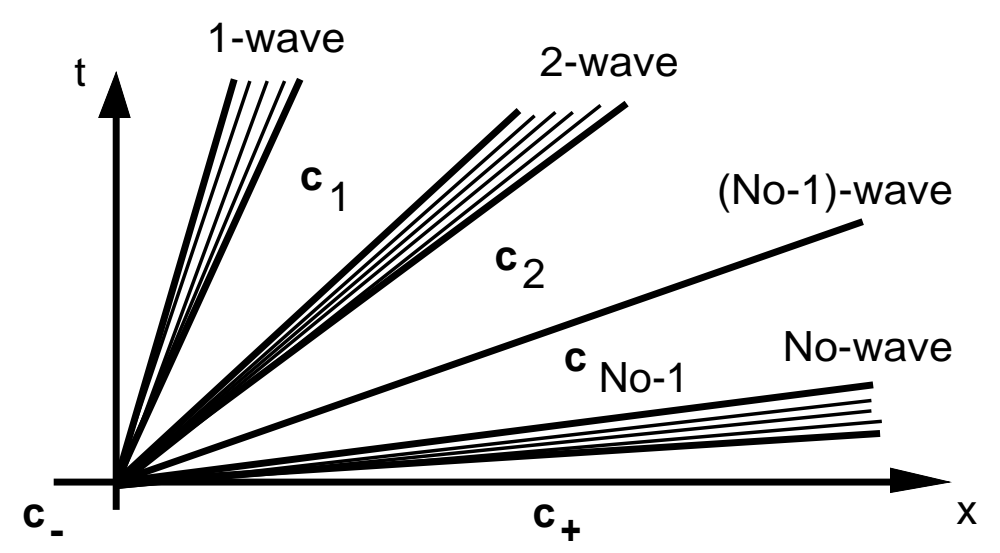

Fig. 2: In a system with $\mathrm{N}_{0}$ components an initial discontinuity $\mathbf{c}_{-} \rightarrow \mathbf{c}_{+}$decomposes with time into a fan of $\mathrm{N}_{0}$ concentration changes (centered waves, bounded by heavy lines), separated by $\mathrm{N}_{0}-1$ constant states $\mathbf{c}_{1}, \mathbf{c}_{2}, \ldots, \mathbf{c}_{\mathrm{No}-1}$. Notation has been chosen according to conventions in mathematics.

It is helpful to represent the concentration profile $\mathbf{c}(\mathrm{x}, \mathrm{t})=\mathbf{h}(\xi)$ in concentration space (called "composition space" by Helfferich and Klein (1970)). As an example, figure 3 shows the two waves of figure $1 \mathrm{~b}$. The concentration space has two axes, the $\mathrm{M}$ - and the $\mathrm{H}$-axis. The constant state $\mathbf{c}_{-}=\left\{M_{-}, H_{-}\right\}$is connected by the 1-wave to the middle state $\mathbf{c}_{1}=\left\{\mathrm{M}_{1}, \mathrm{H}_{1}\right\}$, which in turn is connected by the 2-wave to the constant state $\mathbf{c}_{+}=\left\{\mathrm{M}_{+}, \mathrm{H}_{+}\right\}$.

By definition of the 1-wave, point $\left\{\mathrm{M}_{1}, \mathrm{H}_{1}\right\}$ moves on the 1-wave when point $\left\{\mathrm{M}_{+}, \mathrm{H}_{+}\right\}$is varied and point $\left\{\mathrm{M}_{-}, \mathrm{H}_{-}\right\}$remains fixed. The definition of the 2-wave is similar: It is the curve on which point $\left\{\mathrm{M}_{1}\right.$, $\left.\mathrm{H}_{1}\right\}$ moves when point $\left\{\mathrm{M}_{-}, \mathrm{H}_{-}\right\}$is shifted in $\{\mathrm{M}, \mathrm{H}\}$ space while point $\left\{\mathrm{M}_{+}, \mathrm{H}_{+}\right\}$stays immobile.

The shapes of the waves reflect the chemical interactions in the system. In figure 2 they are arbitrarily represented as lines. The correspondence between their shape and the thermodynamic constants is the subject of the second part of this paper (sections 7 -9). 


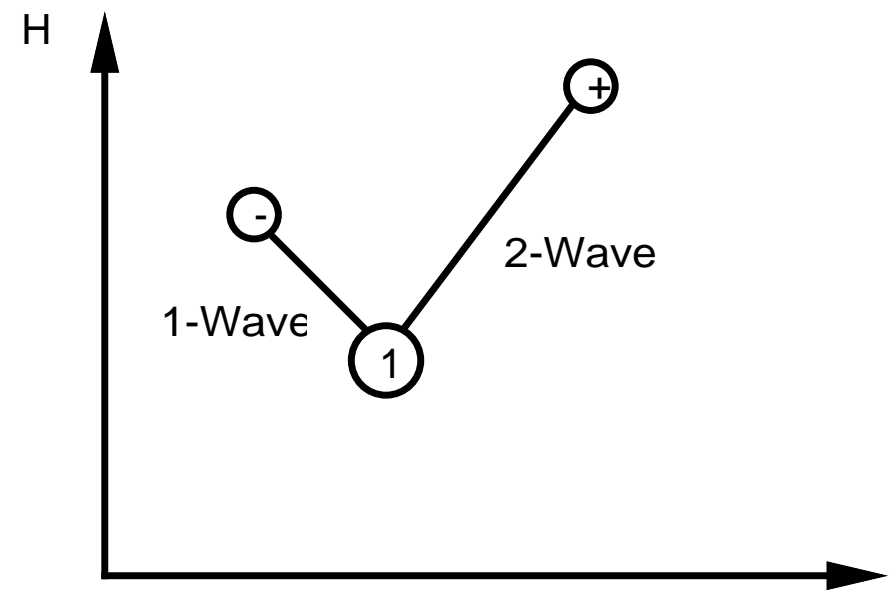

Fig. 3: Waves (shown arbitrarily as lines) and constant states (points (-), (1) and $(+))$ in 2-dimensional composition space. Point (-) has the coordinates $\left\{\mathrm{M}_{-}, \mathrm{H}_{-}\right\}$, $(+)$ has the coordinates $\left\{\mathrm{M}_{+}, \mathrm{H}_{+}\right\}$, and (1) represents $\left\{\mathrm{M}_{1}, \mathrm{H}_{1}\right\}$.

For centered waves, the transport equations (3) become ordinary differential equations. With

$$
\xi=\frac{\mathrm{x}}{\mathrm{t}}
$$

the partial derivatives become total derivatives

$$
\begin{aligned}
& \frac{\partial}{\partial \mathrm{x}}=\frac{\partial \xi}{\partial \mathrm{x}} \frac{\mathrm{d}}{\mathrm{d} \xi}=\frac{1}{\mathrm{t}} \frac{\mathrm{d}}{\mathrm{d} \xi}, \\
& \frac{\partial}{\partial \mathrm{t}}=\frac{\partial \xi}{\partial \mathrm{t}} \frac{\mathrm{d}}{\mathrm{d} \xi}=-\frac{\mathrm{x}}{\mathrm{t}^{2}} \frac{\mathrm{d}}{\mathrm{d} \xi}=-\frac{\xi}{\mathrm{t}} \frac{\mathrm{d}}{\mathrm{d} \xi},
\end{aligned}
$$

and with these the transport equations can be written as

$$
\left(\frac{\mathrm{V}_{\mathrm{w}}}{\phi}-\xi\right) \mathrm{h}_{\mathrm{j}}^{\prime}-\frac{\xi}{\phi} \mathrm{H}_{\mathrm{j}}^{\prime}=0 \quad\left(\mathrm{j}=1,2, \ldots, \mathrm{N}_{0}\right)
$$

where the prime designates the derivative with respect to $\xi$, and the vectors of soluble and adsorbed concentrations, respectively, are defined as 
$\mathbf{h}(\xi)=\left[\begin{array}{c}\mathrm{h}_{1}(\xi) \\ \ldots \\ \mathrm{h}_{\mathrm{N}_{0}}(\xi)\end{array}\right]=\left[\begin{array}{c}\mathrm{c}_{1}(\mathrm{x}, \mathrm{t}) \\ \ldots \\ \mathrm{c}_{\mathrm{N}_{0}}(\mathrm{x}, \mathrm{t})\end{array}\right] ; \quad \mathbf{H}(\mathbf{h}(\xi))=\left[\begin{array}{c}\mathrm{H}_{1}(\mathbf{h}(\xi)) \\ \ldots \\ \mathrm{H}_{\mathrm{N}_{0}}(\mathbf{h}(\xi))\end{array}\right]=\left[\begin{array}{c}\mathrm{C}_{1}^{*}(\mathbf{c}(\mathrm{x}, \mathrm{t})) \\ \ldots \\ \mathrm{C}_{\mathrm{N}_{0}}^{*}(\mathbf{c}(\mathrm{x}, \mathrm{t}))\end{array}\right] .(8)$

\section{Analytical Integration of Transport Equations}

If the sum of the adsorbed component concentrations $\mathrm{H}_{\mathrm{j}}$ is a constant, e.g. a (constant) multiple of the concentration of adsorption sites,

$\sum_{\mathrm{k}=1}^{\mathrm{N}_{0}} \mathrm{H}_{\mathrm{k}}=\mathrm{n} \mathrm{X}_{\mathrm{T}}$

or

$\sum_{\mathrm{k}=1}^{\mathrm{N}_{0}} \mathrm{H}_{\mathrm{k}}^{\prime}=0$

the sum of the set of equations (7) is simply

$\left(\frac{\mathrm{V}_{\mathrm{W}}}{\phi}-\xi\right) \sum_{\mathrm{k}=1}^{\mathrm{N}} \mathrm{h}_{\mathrm{k}}{ }^{\prime}=0$

Possible solutions are

$\xi=\frac{\mathrm{V}_{\mathrm{w}}}{\phi}$ together with $\mathrm{H}_{\mathrm{j}}^{\prime}=0 \quad$ (non-retarded wave)

$\sum_{\mathrm{k}=1}^{\mathrm{N}_{0}} \mathrm{~h}_{\mathrm{k}}{ }^{\prime}=0 \quad$ (retarded waves)

When the number $\mathrm{N}_{0}$ of components is two, the waves are readily plotted as contour lines. The retarded wave is the line on which $\mathrm{h}_{1}+$ $\mathrm{h}_{2}$ is constant, the non-retarded wave is the line on which any adsorbed component concentration $\mathrm{H}_{\mathrm{j}}$ is constant. High level programming languages, e.g. Mathematica (Wolfram Research, 1992), make it easy to plot contour lines of these conserved quantities, $\mathrm{h}_{1}+$ $\mathrm{h}_{2}$ and $\mathrm{H}_{\mathrm{j}}$, in concentration space (see figure 8 below). 


\section{Coherence Conditions, Rankine-Hugoniot Relation and Retardations}

Solving (7) for $\xi=\xi(\mathbf{h})$ we get
$=\frac{\mathrm{v}_{\mathrm{w}}}{\phi} \frac{1}{1+\frac{1}{\phi} \frac{\mathrm{H}_{\mathrm{j}}^{\prime}}{\mathrm{h}_{\mathrm{j}}^{\prime}}}=\frac{\mathrm{v}_{\mathrm{w}}}{\phi} \frac{1}{1+\frac{1}{\phi} \frac{\mathrm{d} \mathrm{H}_{\mathrm{j}} / \mathrm{d} \xi}{\mathrm{dh} / \mathrm{d} \xi}}=\frac{\mathrm{v}_{\mathrm{w}}}{\phi} \frac{1}{1+\frac{1}{\phi} \frac{\mathrm{dH}_{\mathrm{j}}}{\mathrm{dh}_{\mathrm{j}}}} \quad\left(\mathrm{j}=1, \ldots, \mathrm{N}_{0}\right)$

The directional derivative $\mathrm{dH}_{\mathrm{j}} / \mathrm{dh}_{\mathrm{j}}$ (i.e. the change of the adsorbed concentration across the wave, $\mathrm{dH}_{\mathrm{j}} / \mathrm{d} \xi$, divided by the change of the soluble concentration, $\mathrm{dh}_{\mathrm{j}} / \mathrm{d} \xi$ ) depends on the wave along which it is evaluated. Let $\mathrm{k}$ be the index for the $\mathrm{k}$-wave, then for any $\mathrm{k}(1 \leq \mathrm{k} \leq$ $\left.\mathrm{N}_{0}\right)$

$$
\xi_{\mathrm{k}}=\frac{\mathrm{v}_{\mathrm{w}}}{\phi} \frac{1}{1+\frac{1}{\phi} \frac{\mathrm{d} H_{\mathrm{j}} / \mathrm{d} \xi_{\mathrm{k}}}{\mathrm{dh} / \mathrm{d} \xi_{\mathrm{k}}}} \quad\left(\mathrm{j}=1,2, \ldots, \mathrm{N}_{0}\right)
$$

The $\mathrm{k}$ solutions of (13), i.e. of

$$
\frac{\mathrm{dH}_{1} / \mathrm{d} \xi}{\mathrm{dh}_{1} / \mathrm{d} \xi}=\frac{\mathrm{dH} \mathrm{H}_{2} / \mathrm{d} \xi}{\mathrm{dh} / 2 / \mathrm{d} \xi}=\ldots=\frac{\mathrm{dH}_{\mathrm{N}_{0}} / \mathrm{d} \xi}{\mathrm{dh}_{\mathrm{N}_{0}} / \mathrm{d} \xi}
$$

or of

$$
\frac{\mathrm{dH}_{1}}{\mathrm{dh}}=\frac{\mathrm{dH}_{1}}{\mathrm{dh}_{2}}=\ldots=\frac{\mathrm{dH}_{\mathrm{N}_{0}}}{\mathrm{dh}_{\mathrm{N}_{0}}}
$$

are also solutions of the set of conservation laws (3). (15) has been given the name "differential coherence condition" in chromatography (Helfferich and Klein, 1970).

If the isotherms are known functions $\mathrm{H}_{\mathrm{j}}(\mathbf{h})=\mathrm{C}_{\mathrm{j}}{ }^{*}(\mathbf{c})$ of the vector of soluble concentrations, the directional derivative is

$$
\frac{\mathrm{d}}{\mathrm{d} \xi}=\sum_{\mathrm{j}=1}^{\mathrm{N}_{0}} \frac{\partial}{\partial \mathrm{h}_{\mathrm{j}}} \frac{\mathrm{dh_{j }}}{\mathrm{d \xi}}
$$


and (14) can be integrated. The k roots of (14) are the k solutions of the Riemann problem.

The procedure will be illustrated for the general two-component system. We start with the differential coherence condition in the form (14) and then apply the chain rule (16) to expand $d / d \xi$ :

$\frac{\mathrm{dH}_{1} / \mathrm{d} \xi}{\mathrm{dh}_{1} / \mathrm{d} \xi}=\frac{\mathrm{dH}_{2} / \mathrm{d} \xi}{\mathrm{dh} / \mathrm{d} \xi}$

$\frac{\mathrm{dH}_{1} / \mathrm{d} \xi}{\mathrm{dh} / \mathrm{d} \xi}=\frac{\partial \mathrm{H}_{1}}{\partial \mathrm{h}_{1}}+\frac{\partial \mathrm{H}_{1}}{\partial \mathrm{h}_{2}} \frac{\mathrm{dh}_{2} / \mathrm{d} \xi}{\mathrm{dh} / \mathrm{d} \xi}=\frac{\partial \mathrm{H}_{1}}{\partial \mathrm{h}_{1}}+\frac{\partial \mathrm{H}_{1}}{\partial \mathrm{h}_{2}} \frac{\mathrm{dh}_{2}}{\mathrm{dh}_{1}}$

$\frac{\mathrm{dH}_{2} / \mathrm{d} \xi}{\mathrm{dh} / \mathrm{d} \xi}=\frac{\partial \mathrm{H}_{2}}{\partial \mathrm{h}_{1}} \frac{\mathrm{dh}_{1} / \mathrm{d} \xi}{\mathrm{dh} / 2 / \mathrm{d} \xi}+\frac{\partial \mathrm{H}_{2}}{\partial \mathrm{h}_{2}}=\frac{\partial \mathrm{H}_{1}}{\partial \mathrm{h}_{1}} \frac{\mathrm{dh}_{1}}{\mathrm{dh}_{2}}+\frac{\partial \mathrm{H}_{1}}{\partial \mathrm{h}_{2}}$

With (18) and (19) equation (17) becomes a quadratic equation for $\mathrm{dh}_{2} / \mathrm{dh}_{1}$ with known coefficients $\mathrm{p}$ and $\mathrm{q}$

$\left(\frac{\mathrm{dh}_{2}}{\mathrm{dh}_{1}}\right)^{2}+\mathrm{p} \frac{\mathrm{dh}_{2}}{\mathrm{dh}_{1}}+\mathrm{q}=0$

where

$\mathrm{p}=\left(\frac{\frac{\partial \mathrm{H}_{1}}{\partial \mathrm{h}_{1}}-\frac{\partial \mathrm{H}_{2}}{\partial \mathrm{h}_{2}}}{\frac{\partial \mathrm{H}_{1}}{\partial \mathrm{h}_{2}}}\right), \mathrm{q}=-\left(\frac{\frac{\partial \mathrm{H}_{2}}{\partial \mathrm{h}_{1}}}{\frac{\partial \mathrm{H}_{1}}{\partial \mathrm{h}_{2}}}\right)$

There are two roots of (20), one for the 1-wave and the other for the 2-wave

$\frac{\mathrm{dh} h_{2}}{\mathrm{dh} h_{1}}=-\frac{\mathrm{p}}{2} \pm \sqrt{\frac{\mathrm{p}^{2}}{4}-\mathrm{q}}$.

High level programming languages such as Mathematica (Wolfram Research, 1992) can be readily used to calculate the waves from (22). These languages give analytical functions $h_{2}\left(h_{1}\right)$ when they can find them, and interpolating polynomials otherwise. 
Similarly, the speed of the k-wave can be calculated, once the solutions $\mathbf{h}_{\mathrm{k}}(\xi)=\left\{\mathrm{h}_{1}(\xi), \mathrm{h}_{2}(\xi), \ldots, \mathrm{h}_{\mathrm{No}}(\xi)\right)$ are known. According to (13), the speed of the k-rarefaction wave is by a factor (the so-called "retardation")

$\mathrm{R}_{\mathrm{k}}=1+\frac{1}{\phi} \frac{\mathrm{dH}_{\mathrm{j}} / \mathrm{d} \xi_{\mathrm{k}}}{\mathrm{dh} / \mathrm{d} \xi_{\mathrm{k}}} \quad\left(\mathrm{j}=1,2, \ldots, \mathrm{N}_{0}\right)$

smaller than the pore water velocity $\mathrm{v}_{\mathrm{w}} / \phi$. Note that (23) states that all components $A_{j}\left(j=1,2, \ldots, N_{0}\right)$ experience the same retardation $R_{k}$ in the k-wave.

Rarefaction waves are not the only type of solution of the mass conservation law (3). The existence of the second type, the shock, will not be proved. The proof of the existence of shocks (Lax, 1957) will be replaced by a plausibility argument.

Suppose that the retardation $\mathrm{R}_{\mathrm{k}}(\mathbf{h})$ decreases with increasing concentration $\mathbf{h}$. When the rear end of a wave (e.g. point $\mathbf{c}_{\text {- of }}$ the 1-wave in figure 2) has a lower retardation than its front (point $\mathbf{c}_{1}$ in figure 2), the rear will travel faster than the front. The corresponding concentration profil $\mathbf{c}(\mathrm{x}, \mathrm{t})$ will become steeper (sharper) as the wave proceeds. A concentration wave steepens until it has developed a discontinuity and is just about to break (in the sense a water wave breaks). From then on all concentrations travel with the same speed. The resulting concentration discontinuity is the shock. Contrary to a concentration wave, the water wave develops beyond this point and actually breaks, i.e. the portions in the upper part of the wave overtake the ones in the lower part. The shock wave travels with a speed given by the conservation of mass across the shock.

Appendix 12 A. 3 shows that the mass balance involves finite rather than infinitesimal quantities, if the wave is a shock (Lax, 1973). The speed of the shock is given by the Rankine-Hugoniot relation

$\sigma_{\mathrm{k}}=\frac{\mathrm{V}_{\mathrm{w}}}{\phi} \frac{\Delta \mathrm{c}_{\mathrm{j}}}{\Delta\left(\mathrm{c}_{\mathrm{j}}+\frac{1}{\phi} \mathrm{C}_{\mathrm{j}}^{*}\right)}=\frac{\mathrm{v}_{\mathrm{w}}}{\phi} \frac{1}{1+\frac{1}{\phi} \frac{\Delta \mathrm{C}_{\mathrm{j}}^{*}}{\Delta \mathrm{c}_{\mathrm{j}}}}=\frac{\mathrm{v}_{\mathrm{w}}}{\phi} \frac{1}{\mathrm{R}_{\mathrm{k}}} \quad\left(\mathrm{j}=1,2, \ldots, \mathrm{N}_{0}\right)$

where the symbol $\Delta$ denotes the change across the k-shock. In mathematics the symbol \|\| is often used instead of $\Delta$. Using $\mathrm{h}$ and $\mathrm{H}$ instead of $\mathrm{c}$ and $\mathrm{C}^{*}$ 


$$
\sigma_{\mathrm{k}}=\frac{\mathrm{V}_{\mathrm{w}}}{\phi} \frac{1}{1+\frac{1}{\phi} \frac{\Delta \mathrm{H}_{\mathrm{j}}}{\Delta \mathrm{h}_{\mathrm{j}}}} \quad\left(\mathrm{j}=1,2, \ldots, \mathrm{N}_{0}\right)
$$

The set of equations

$\frac{\Delta \mathrm{H}_{1}}{\Delta \mathrm{h}_{1}}=\frac{\Delta \mathrm{H}_{2}}{\Delta \mathrm{h}_{2}}=\ldots=\frac{\Delta \mathrm{H}_{\mathrm{N}_{0}}}{\Delta \mathrm{h}_{\mathrm{N}_{0}}}$

is called "integral coherence condition" in chromatography and is used to calculate the concentration changes $\Delta \mathrm{h}_{\mathrm{j}}$ across the shocks (Lax, 1973).

The third solution method is based on the Jacobi-matrix of the adsorption isotherms $\mathrm{C}^{*}{ }_{\mathrm{j}}(\mathbf{c})$. It is the most general of the solution methods.

\section{The Jacobian and the Retardation Matrix}

Because the adsorbed concentrations $\mathrm{H}_{\mathrm{j}}=\mathrm{C}^{*}{ }_{\mathrm{j}}(\mathbf{c})$ depend only on the soluble concentrations, the derivatives with respect to $\xi$ could be re-written using the chain rule (16). The transport equation (7) becomes then

$$
\left(\frac{\mathrm{V}_{\mathrm{w}}}{\phi}-\xi\right) \mathrm{h}_{\mathrm{j}}^{\prime}-\frac{\xi}{\phi} \sum_{\mathrm{k}=1}^{\mathrm{N}_{0}} \frac{\partial \mathrm{C}_{\mathrm{j}}^{*}}{\partial \mathrm{c}_{\mathrm{k}}} \mathrm{h}_{\mathrm{k}}^{\prime}=0
$$

or -after division by $\xi$ and rearrangement- in matrix form

$$
\left\{\underline{\mathrm{I}}+\frac{1}{\phi} \underline{\mathrm{Kd}}\right\} \mathbf{h}^{\prime}=\frac{\mathrm{V}_{\mathrm{w}}}{\phi} \frac{1}{\xi} \mathbf{h}^{\prime} .
$$

$\underline{I}$ is the identity matrix and $\underline{\mathrm{Kd}}$ is composed of the partial derivatives of the adsorption isotherms $\mathrm{C}_{\mathrm{j}}^{*}$ 


$$
\underline{\mathrm{I}}=\left[\begin{array}{ccc}
1 & \ldots & 0 \\
\ldots & 1 & \ldots \\
0 & \ldots & 1
\end{array}\right], \quad \underline{\mathrm{Kd}}(\mathbf{c})=\left[\begin{array}{ccc}
\frac{\partial \mathrm{C}_{1}^{*}}{\partial \mathrm{c}_{1}} & \ldots & \frac{\partial \mathrm{C}_{1}^{*}}{\partial \mathrm{c}_{\mathrm{N}_{0}}} \\
\ldots & \ldots & \ldots \\
\frac{\partial \mathrm{C}_{\mathrm{N}_{0}}^{*}}{\partial \mathrm{c}_{1}} & \ldots & \frac{\partial \mathrm{C}_{\mathrm{N}_{0}}^{*}}{\partial \mathrm{c}_{\mathrm{N}_{0}}}
\end{array}\right] .
$$

I will introduce the matrix $\underline{\mathrm{R}}(\mathbf{c})$, the "retardation matrix":

$$
\underline{\mathrm{I}}+\frac{1}{\phi} \underline{\mathrm{Kd}}(\mathbf{c})=\underline{\mathrm{R}}(\mathbf{c}) .
$$

With the abbreviation (30) the system of transport equations (7) can be written as an eigenvalue problem

$\underline{\mathrm{R}} \mathbf{h}^{\prime}(\xi)=\frac{\mathrm{V}_{\mathrm{w}}}{\phi} \frac{1}{\xi} \mathbf{h}^{\prime}(\xi)$.

This set of equations is satisfied when

$\rho(\mathbf{h})=\frac{\mathrm{V}_{\mathrm{W}}}{\phi} \frac{1}{\xi(\mathbf{h})}$

is an eigenvalue of the retardation matrix $\underline{\mathrm{R}}$ evaluated at the point $\mathbf{c}=$ $\mathbf{h}$ in composition space, and when $\mathbf{h}$ ', the change of $\mathbf{h}$, is parallel to the right eigenvector corresponding to $\rho(\mathbf{h})$

$\mathbf{h}^{\prime}=\boldsymbol{\gamma} \mathbf{r}(\mathbf{h})$.

I will normalize $\mathbf{r}$ such that $\gamma=1$.

The system (7) is genuinely nonlinear, and the direction of $\mathbf{r}$ is chosen such that it points in the direction of decreasing retardation

$\mathbf{r} \operatorname{grad} \rho(\mathbf{h})<0$

$\mathbf{h}^{\prime} \operatorname{grad} \rho(\mathbf{h})<0 \quad$ (rarefaction wave),

where $\operatorname{grad}=\left\{\partial / \partial \mathrm{c}_{1}, \partial / \partial \mathrm{c}_{2}, \ldots, \partial / \partial \mathrm{c}_{\mathrm{No}_{\mathrm{o}}}\right\}$ is the change across the wave. For example, in figure 3 the change of the retardation at $\mathbf{c}_{-}$in direction to $\mathbf{c}_{1}$ is $\operatorname{grad} \rho_{1}\left(\mathbf{c}_{-}\right)$, where the index on $\rho$ indicates the wave. Furthermore, if -as assumed in figure 3 - the waves are lines, $\mathbf{r}_{1}\left(\mathbf{c}_{-}\right)$and $\mathbf{h}_{1}{ }^{\prime}\left(\mathbf{c}_{-}\right)$are vectors that are colinear with the 1-wave. If the retardation 
$\rho_{1}\left(\mathbf{h}_{1}\right)$ of the 1-wave decreases from $\mathbf{c}_{-}$to $\mathbf{c}_{1}$, the vectors $\mathbf{r}_{1}\left(\mathbf{c}_{-}\right)$and $\mathbf{h}_{1}{ }^{\prime}\left(\mathbf{c}_{-}\right)$point from $\mathbf{c}_{-}$to $\mathbf{c}_{1}$.

For a shock, the retardation increases in the direction of $\mathbf{h}^{\prime}$ :

$\mathbf{h}^{\prime} \operatorname{grad} \rho(\mathbf{h})>0 \quad$ (shock).

The retardations $\rho_{\mathrm{j}}(\mathbf{c})$ will be arranged in decreasing order. None of the retardations is smaller than 1:

$\rho_{1} \geq \rho_{2} \geq \rho_{3} \geq \ldots \geq \rho_{\mathrm{N}_{0}} \geq 1$.

According to (33) the change $\mathbf{h}_{\mathrm{k}}$ ' of a concentration $\mathbf{h}_{\mathrm{k}}$ is parallel to the k-eigenvector $\mathbf{r}_{\mathrm{k}}$ at point $\mathbf{h}_{\mathrm{k}}$. The k-rarefaction wave is the entity of all such changes. It follows from that the k-rarefaction wave is the curve that is everywhere tangential to $\mathbf{r}_{\mathrm{k}}$ and can be constructed with a suitable Runge-Kutta method (Zielke, 1993). Such methods are incorporated in the high level computer languages AVS (Application Visualization System (International AVS Center)) or Mathematica (Wolfram Redearch, 1992). AVS constructs the k-wave on the computer screen after having received the vector field $\mathbf{r}_{\mathrm{k}}(\mathbf{c})$ and the user has pressed the corresponding button.

\section{Topology of Waves for Multicomponent Langmuir Type Isotherms}

\subsection{Isotherms}

Three Langmuir type isotherms will be presented here, i.e. for multicomponent ligand exchange, for adsorption via surface bridge formation, and for surface complexation on variable charge interfaces at low ionic stregths. Let $\mathrm{N}_{0}$ be the number of adsorbed species $\underline{A}_{1}$, $\underline{\mathrm{A}}_{2}, \ldots, \underline{\mathrm{A}}_{\underline{\mathrm{NO}}}$. The adsorptive bond is described by a set of parameters that are called "separation factors" $\alpha_{\mathrm{j}}$ or adsorption constants $\mathrm{k}_{\mathrm{j}}$, depending on the adsorption process.

\subsubsection{Ligand Exchange}


Unlike ion exchange processes, in which the surface bond is electrostatic, surface complexation is a predominantly chemical process. Complex formation -be it in solution or on surfaces- can bind electrically charged species together even if they carry charges of the same polarity. The surface complexation process changes the charge of surfaces. Thus, superimposed on the fixed chemical bond is an electrostatic bond that varies with the surface coverage, and thus with the composition c of the solution (Dzombak and Morel, 1990).

Separation factors $\alpha_{\mathrm{iN}}$ describe the exchange on the surface of ions or ligands $A_{N}$ and $A_{i}$ (see figure 4 ):

$\underline{A}_{N}+A_{j}=\underline{A}_{j}+A_{N}, \quad\left(j=1,2, \ldots, N_{0}, j \neq N\right)$.

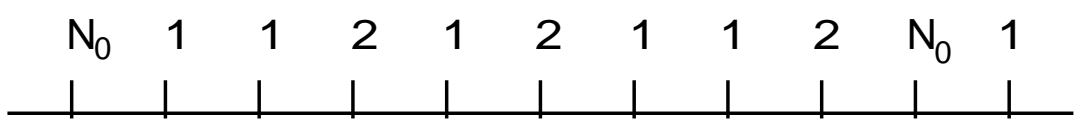

Fig. 4: Schematic of surface when adsorption process is ion or ligand exchange. Sites are occupied by components (ligands) $\mathrm{A}_{1}, \mathrm{~A}_{2}, \ldots, \mathrm{A}_{\mathrm{N}}$, represented by the numbers $1,2, \ldots, \mathrm{N}_{0}$. The adsorbed concentrations are described by isotherm (41). If $\mathrm{c}_{\mathrm{N}}$ or the sum of the soluble concentrations of the adsorbing species is constant, the isotherm degenerates to a Langmuir type isotherm (46).

An example is the surface complexation of heavy metal cations $\mathrm{M}^{2+}$ on hydrous ferric oxides $\left(\mathrm{M}^{2+}=\mathrm{Ag}^{2+}, \mathrm{Ca}^{2+}, \mathrm{CrOH}^{2+}, \mathrm{Cu}^{2+}\right.$, $\mathrm{Ni}^{2+}, \mathrm{Pb}^{2+}, \mathrm{Sr}^{2+}$ and of $\mathrm{SrOH}^{+}$) (Dzombak and Morel, 1990). Let X represent the crystal lattice of the oxide and $\mathrm{O}$ the layer of oxygen atoms at the solid-liquid interface. The surface species involved in the adsorption process are then $\mathrm{X}-\mathrm{OH}$ and $\mathrm{X}-\mathrm{OM}^{+}$. The adsorption reaction is

$\mathrm{X}-\mathrm{OH}+\mathrm{M}^{2+}=\mathrm{X}-\mathrm{OM}^{+}+\mathrm{H}^{+}$.

Using the symbol $\mathrm{C}_{\mathrm{j}}^{*}$ for the concentration of the surface species $\underline{A}_{i}$ and $c_{j}$ for the concentration of the adsorbing species, the mass action law for the adsorption reaction (36) is

$C_{j}^{*}(\mathbf{c})=\alpha_{j N} \frac{C_{N}^{*}(\mathbf{c})}{c_{N}} c_{j}, \quad\left(j=1,2, \ldots, N_{0}\right)$ 
Note that $\alpha_{\mathrm{NN}}=1$. Because all surface sites are assumed to be filled, the sum of the surface species concentrations is equal to the concentration of surface sites

$$
\sum_{\mathrm{l}=1}^{\mathrm{N}_{0}} \mathrm{C}_{\mathrm{l}}^{*}(\mathbf{c})=\mathrm{X}_{\mathrm{T}}=\frac{\mathrm{C}_{\mathrm{N}}^{*}}{\mathrm{C}_{\mathrm{N}}} \sum_{\mathrm{l}=1}^{\mathrm{N}_{0}} \alpha_{1 \mathrm{~N}} \mathrm{c}_{\mathrm{l}}
$$

or

$$
\frac{\mathrm{C}_{\mathrm{N}}^{*}}{\mathrm{c}_{\mathrm{N}}}=\frac{\mathrm{X}_{\mathrm{T}}}{\sum_{\mathrm{l}=1}^{\mathrm{N}_{0}} \alpha_{1 \mathrm{~N}} \mathrm{c}_{\mathrm{l}}} .
$$

After replacing $\mathrm{C}_{\mathrm{N}}{ }^{*} / \mathrm{c}_{\mathrm{N}}$ in (38) with the expression in (40) we get the isotherm

$$
C_{j}^{*}(\mathbf{c})=X_{T} \frac{\alpha_{j N} c_{j}}{\sum_{l=1}^{N} \alpha_{1 N} c_{l}}, \quad\left(j=1,2, \ldots, N_{0}\right)
$$

Note that the selectivity coefficients $\alpha_{j N}$ depend on the electric surface charge. If the latter is variable -as it is on metal oxides- it will be separated from the $\alpha$ 's and the selectivity coefficient will be written as $\alpha_{\mathrm{jN}} \mathrm{P}_{\mathrm{L}}^{\Delta \mathrm{z}}$ with

$P_{L}=\exp \left(-\frac{F \psi_{L}}{R T}\right)$.

$\Delta \mathrm{z}$ is the change of the charge of the adsorbing layer $\mathrm{L}$ (in units of the electric charge, $\mathrm{e}=\mathrm{F} / \mathrm{N}_{\mathrm{A}}, \mathrm{N}_{\mathrm{A}}$ being the number of particles in a mol) in the surface complexation reaction. $\Delta \mathrm{z}$ is +1 for reaction (37) involving the exchange of a doubly charged metal ion with the proton. $\psi_{\mathrm{L}}$ (unit: Volt $=$ Joule/Coulomb) is the electrostatic potential in the adsorbing layer L on the oxide, F (96485 Coulomb/mol) is the Faraday-constant, $\mathrm{R}(8.31 \mathrm{Joule} /(\mathrm{mol} \mathrm{K})$ is the general gas constant and $\mathrm{T}$ (unit: $\mathrm{K}$ ) is the absolute temperature.

The electrostatic correction factor is a simple function of $\mathrm{pH}$ at low ionic strengths and small metal concentrations in solution. In section 8 it will be shown that the isotherms assume a particularly simple form in that case. 


\subsubsection{Surface Bridge Formation}

Adsorption can be the formation of bridges between a surface ligand $A_{N}$ and components $A_{j}$ (see figure 5). The surface species $\underline{A}_{N}$ is called "empty surface site". It is thus not counted among the $\mathrm{N}_{0}$ surface species $\underline{A}_{\underline{N}} \underline{A}_{j}$.

$\underline{\mathrm{A}}_{\mathrm{N}}+\mathrm{A}_{\mathrm{j}}=\underline{\mathrm{A}}_{\mathrm{N}} \underline{\mathrm{A}}_{j}, \quad\left(\mathrm{j}=1,2, \ldots, \mathrm{N}_{0}\right)$

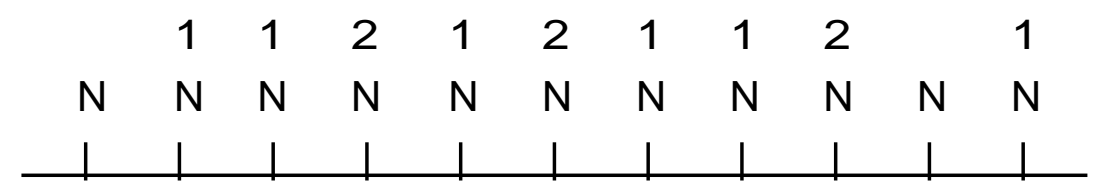

Fig. 5: Schematic of surface when adsorption process is bridge formation between a component (ligand) $A_{N}$ and components $A_{1}, A_{2}, \ldots, A_{N-0}$. The surface sites $\underline{A}_{N}$ are sometimes called "empty". Adsorption isotherms for bridge formation ane of Langmuir type (46).

On oxides $\underline{A}_{N}$ is sometimes written as $\mathrm{X}-\mathrm{OH}$. An example is the surface complexation of $\mathrm{M}^{2+}=\mathrm{Ba}^{2+}, \mathrm{Ca}^{2+}, \mathrm{Sr}^{2+}$ (Dzombak and Morel, 1990)

$\mathrm{X}-\mathrm{OH}+\mathrm{M}^{2+}=\mathrm{X}-\mathrm{OHM}^{2+}$.

Adsorbed species concentrations are proportional to $\mathrm{C}^{*}{ }_{\mathrm{N}}$ and $\mathrm{c}_{\mathrm{j}}$ (the soluble concentration of the adsorbed species). The mass action law here is

$\mathrm{C}_{\mathrm{j}}^{*}(\mathbf{c})=\mathrm{k}_{\mathrm{j}} \mathrm{C}_{\mathrm{N}}^{*} \mathrm{c}_{\mathrm{j}}, \quad\left(\mathrm{j}=1,2, \ldots, \mathrm{N}_{0}, \mathrm{j} \neq \mathrm{N}\right)$.

The concentration $\mathrm{C}^{*}{ }_{\mathrm{N}}$ of the empty sites can be expressed as a fraction of the total concentration of sites, similarly as it was done in (38).

$\sum_{\mathrm{l}=1}^{\mathrm{N}_{0}} \mathrm{C}_{\mathrm{l}}^{*}=\mathrm{X}_{\mathrm{T}}=\mathrm{C}_{\mathrm{N}}^{*}\left(1+\sum_{\substack{l=1 \\ \mathrm{l} \neq \mathrm{N}}}^{\mathrm{N}_{0}} \mathrm{k}_{\mathrm{j}} \mathrm{c}_{\mathrm{j}}\right)$

or 


$$
\mathrm{C}_{\mathrm{N}}^{*}=\frac{\mathrm{X}_{\mathrm{T}}}{1+\sum_{\substack{1=1 \\ 1 \neq \mathrm{N}}}^{\mathrm{N}_{0}} \mathrm{k}_{\mathrm{j}} \mathrm{c}_{\mathrm{j}}}
$$

Thus

$$
\mathrm{C}_{\mathrm{j}}^{*}(\mathbf{c})=\mathrm{X}_{\mathrm{T}} \frac{\mathrm{k}_{\mathrm{j}} \mathrm{c}_{\mathrm{j}}}{1+\sum_{\substack{\mathrm{l}=1 \\ 1 \neq \mathrm{N}}}^{\mathrm{N}_{0}} \mathrm{k}_{\mathrm{l}} \mathrm{c}_{\mathrm{l}}}, \quad\left(\mathrm{j}=1,2, \ldots, \mathrm{N}_{0}, \mathrm{j} \neq \mathrm{N}\right)
$$

Again, the adsorption constants $\mathrm{k}_{\mathrm{j}}$ depend on the electrostatic potential in the adsorbing layer, and when the potential varies due to the variation of the surface charge, its effect will be separated from the constant and the adsorption constant will be written as $\mathrm{k}_{\mathrm{j}} \mathrm{P}_{\mathrm{L}}^{\Delta \mathrm{z} \text {. }}$

The concentration $\mathrm{C}^{*}{ }_{\mathrm{N}}$ of empty sites decreases with increasing concentrations $\mathrm{c}_{1}, \mathrm{c}_{2}, \ldots, \mathrm{c}_{\mathrm{No}}$ as more and more surface bridges are built. The same happens obviously when adsorption is an exchange process (36) and

(1) one adsorbing species, e.g. $A_{N}$, has a constant concentration in solution. In that case, the isotherm (41) degenerates to the Langmuir isotherm (46).

(2) when the sum of the soluble concentrations of the exchanging species is a constant, c

$$
\sum_{1=1}^{\mathrm{N}_{0}} \mathrm{c}_{\mathrm{l}}=\mathrm{c}
$$

Then according to (41) the adsorbed concentrations are as given in the following equation (48)

$$
\mathrm{C}_{\mathrm{j}}^{*}(\mathbf{c})=\mathrm{X}_{\mathrm{T}} \frac{\alpha_{\mathrm{jN}} \mathrm{c}_{\mathrm{j}}}{\mathrm{c}_{\mathrm{N}}+\sum_{\substack{\mathrm{l}=1 \\ 1 \neq N}}^{\mathrm{N}_{0}} \alpha_{\mathrm{INCl}}}=\mathrm{X}_{\mathrm{T}} \frac{\frac{\alpha_{\mathrm{jN}}}{\mathrm{c}} \mathrm{c}_{\mathrm{j}}}{1+\sum_{\substack{\mathrm{l}=1 \\ 1 \neq N}}^{\mathrm{N}_{0}} \frac{\alpha_{\mathrm{lN}}-1}{\mathrm{c}} \mathrm{c}_{\mathrm{l}}} .
$$




\subsubsection{Adsorption on Variable Charge Surfaces at Low Ionic Stregths}

The concentrations of surface species on variable surface charge oxides can be calculated from the following adsorption mass action laws, similarly as in the two previous sections. Let $\mathrm{H}$ and $\mathrm{M}$ be the free proton and metal concentrations in solution, $X_{T}$ the total concentration of adsorbing sites on the variable charge oxide surface and $\mathrm{k}_{1}$, $\mathrm{k}_{2}$ and $\alpha$ the adsorption constants for one, two protons and the doubly charged metal -all asumed to adsorb in the same plane (Dzombak and Morel, 1990), then the mass action laws and the surface site balance are

$\mathrm{XOH}_{2}=\mathrm{k}_{1} \mathrm{P} \mathrm{XOH} \mathrm{H}$,

$\mathrm{XO}=\frac{\mathrm{k}_{2}}{\mathrm{P}} \mathrm{XOH} \frac{1}{\mathrm{H}}$,

$\mathrm{XOM}=\alpha \mathrm{P} \mathrm{XOH} \frac{\mathrm{M}}{\mathrm{H}}$,

$\mathrm{X}_{\mathrm{T}}=\mathrm{XOH}_{2}+\mathrm{XOH}+\mathrm{XO}+\mathrm{XOM}$

Combining these four equations, we find the isotherms

$\mathrm{XOH}_{2}(\mathrm{M}, \mathrm{H})=\mathrm{X}_{\mathrm{T}} \frac{\mathrm{k}_{1} \mathrm{P} \mathrm{H} \mathrm{H}^{2}}{\alpha \mathrm{P} \mathrm{M}+\mathrm{H}\left(1+\mathrm{k}_{1} \mathrm{P} \mathrm{H}\right)+\mathrm{k}_{2} / \mathrm{P}}$,

$\mathrm{XOH}(\mathrm{M}, \mathrm{H})=\mathrm{X}_{\mathrm{T}} \frac{\mathrm{H}}{\alpha \mathrm{P} \mathrm{M}+\mathrm{H}\left(1+\mathrm{k}_{1} \mathrm{P} \mathrm{H}\right)+\mathrm{k}_{2} / \mathrm{P}}$,

$\mathrm{XO}(\mathrm{M}, \mathrm{H})=\mathrm{X}_{\mathrm{T}} \frac{\mathrm{k}_{2} / \mathrm{P}}{\alpha \mathrm{P} \mathrm{M}+\mathrm{H}\left(1+\mathrm{k}_{1} \mathrm{P} \mathrm{H}\right)+\mathrm{k}_{2} / \mathrm{P}}$,

$\mathrm{XOM}(\mathrm{M}, \mathrm{H})=\mathrm{X}_{\mathrm{T}} \frac{\alpha \mathrm{P} \mathrm{M}}{\alpha \mathrm{P} \mathrm{M}+\mathrm{H}\left(1+\mathrm{k}_{1} \mathrm{P} H\right)+\mathrm{k}_{2} / \mathrm{P}}$.

At trace concentrations of the metal, $\mathrm{P}$ is a function only of $\mathrm{pH}$ and the ionic strength $\mathrm{I}=1 / 2 \sum \mathrm{z}_{\mathrm{i}}^{2} \mathrm{c}_{\mathrm{i}}$, where $\mathrm{i}$ designates any of the soluble species $A_{i}$ with charge $z_{i}$ present in the system. Dzombak and Morel (1990) have tabulated P. 
If, at small ionic strengths $\mathrm{I} \leq 10^{-4} \mathrm{M}$, the correction factor is approximated by

$\mathrm{P}=\frac{\sqrt{\frac{\mathrm{k}_{2}}{\mathrm{k}_{1}}}}{\mathrm{H}}=\frac{\mathrm{PZC}}{\mathrm{H}}$,

the curves of the approximation and the true $\mathrm{P}$ coincide, as is demonstrated in figure 6 . At the ionic strength $\mathrm{I}=10^{-1} \mathrm{M}$ where many adsorption experiments have been made, the approximation

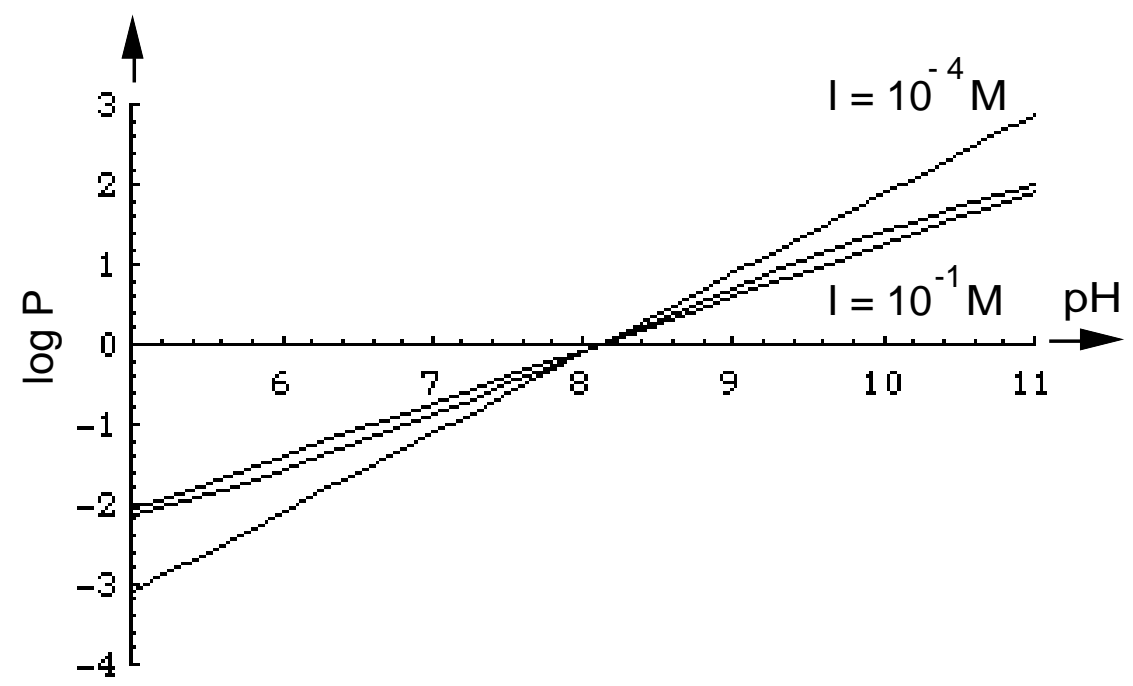

Fig. 6: Electrostatic correction factor $\mathrm{P}$ and its approximations $\mathrm{P}_{\mathrm{a}}$ as a function of $\mathrm{pH}$ for two ionic strengths I (after Dzombak and Morel (1990)). At $\mathrm{I}=10^{-4} \mathrm{M}$, $\mathrm{P}_{\mathrm{a}}$ and $\mathrm{P}$ coincide, at $\mathrm{I}=10^{-1} \mathrm{M}, \mathrm{P}_{\mathrm{a}}$ is the (straight) line.

$\mathrm{P}=\left(\frac{\mathrm{PZC}}{\mathrm{H}}\right)^{2 / 3}$

is good.

A property of approximation (12) is the exact balance between positive and negative surface charges in pristine water,

$\mathrm{XOH}_{2}(\mathrm{M}, \mathrm{H})=\mathrm{XO}(\mathrm{M}, \mathrm{H})$.

The isotherms resemble the ones for exchange of two protons with one metal ion (see (36) and (41)): 
$\mathrm{XOH}_{2}(\mathrm{M}, \mathrm{H})=\mathrm{X}_{\mathrm{T}} \frac{\mathrm{k}_{1} \mathrm{P} \mathrm{H}^{2}}{\alpha \sqrt{\frac{\mathrm{k}_{2}}{\mathrm{k}_{1}}} \mathrm{M}+\left(1+2 \sqrt{\mathrm{k}_{1} \mathrm{k}_{2}}\right) \mathrm{H}^{2}}$,

$\mathrm{XOH}(\mathrm{M}, \mathrm{H})=\mathrm{X}_{\mathrm{T}} \frac{\mathrm{H}^{2}}{\alpha \sqrt{\frac{\mathrm{k}_{2}}{\mathrm{k}_{1}} \mathrm{M}+\left(1+2 \sqrt{\mathrm{k}_{1} \mathrm{k}_{2}}\right) \mathrm{H}^{2}},}$

$\operatorname{XOM}(M, H)=X_{T} \frac{\alpha \sqrt{\frac{\mathrm{k}_{2}}{\mathrm{k}_{1}}} M}{\alpha \sqrt{\frac{\mathrm{k}_{2}}{\mathrm{k}_{1}}} \mathrm{M}+\left(1+2 \sqrt{\mathrm{k}_{1} \mathrm{k}_{2}}\right) \mathrm{H}^{2}}$.

The exchange stoichiometry is reflected in the exponents of the free metal and proton concentrations, e.g. (41) being the isotherm for an exchange of one proton with one metal ion. (60) - (62) lead to an analytical solution of the set of transport equations (7). This solution is a useful guide to systems with H-M exchange, which will be shown in section 8 .

\subsection{Properties of Waves}

\subsubsection{Non-Retarded Waves}

A non-retarded wave appears on two occasions :

(1) The sum of the adsorbed component concentrations is constant (see (9)).

(2) One or several components $A_{j}$ do not adsorb $\left(H_{j}{ }^{\prime}=0\right.$ in (7)).

Condition (1) is characteristic of the isotherm (41). Connected with this is a property of that isotherm : The surface speciation $\mathrm{C}_{\mathrm{j}}{ }^{*}(\mathrm{j}$ $=1,2, \ldots, \mathrm{N}_{0}$ ) remains unchanged when all concentrations $\mathrm{c}_{\mathrm{j}}$ vary by $\mathrm{a}$ common factor

$$
C_{j}^{*}(\mathbf{c})=X_{T} \frac{\alpha_{j N} c_{j}}{\sum_{l=1}^{N_{0}} \alpha_{1 N} c_{l}}=X_{T} \frac{\alpha_{j N} a c_{j}}{\sum_{l=1}^{N_{0}} \alpha_{1 N} \text { a cl }}=C_{j}^{*}(a \mathbf{c}), \quad\left(j=1,2, \ldots, N_{0}\right)
$$


Because the equation of this non-retarded wave is $\mathbf{c}=\mathbf{a} \mathbf{c}_{+}$, the wave lies on a line through the origin of composition space.

Condition (2) is necessary for a non-retarded wave to appear in systems in which adsorption of all components follows isotherms (46) or (48). Unlike for the exchange process (36), the empty site $A_{N}$ does not appear explicitely among the $\mathrm{N}_{0}$ species in the isotherm (46), although it is part of the system. Therefore, any variation of $\mathbf{c}$ causes $\mathrm{C}_{\mathrm{j}}{ }^{*}$ to change, or in other words: $\mathrm{H}_{\mathrm{j}}{ }^{\prime} \neq 0$ for any shift of $\mathbf{c}$. Hence, the non-retarded wave, $v_{\mathrm{w}} / \phi=\xi$, is a solution only if one of the $\mathrm{H}_{\mathrm{j}}$ itself is zero.

\subsubsection{Waves are Lines}

Waves are particularly simple if all site types adsorb according to class (41) and (46) isotherms (Temple (1983), Rhee et al. (1989))

$\mathrm{C}_{\mathrm{j}}^{*}(\mathbf{c})=\sum_{\alpha} \mathrm{X}_{\mathrm{T}}^{\alpha} \frac{\mathrm{k}_{\mathrm{j}}^{\alpha} \mathrm{c}_{\mathrm{j}}}{\delta^{\alpha}(\mathbf{c})} \quad\left(\mathrm{j}=1,2, \ldots, \mathrm{N} \leq \mathrm{N}_{0}\right)$,
$\delta^{\alpha}(\mathbf{c})=\mathrm{b}+\sum_{\mathrm{j}=1}^{\mathrm{N}_{0}} \mathrm{k}_{\mathrm{j}}^{\alpha} \mathrm{c}_{\mathrm{j}}$

where $\mathrm{X}_{\mathrm{T}}^{\alpha}$ is the concentration of adsorption site type $\alpha$, the constant

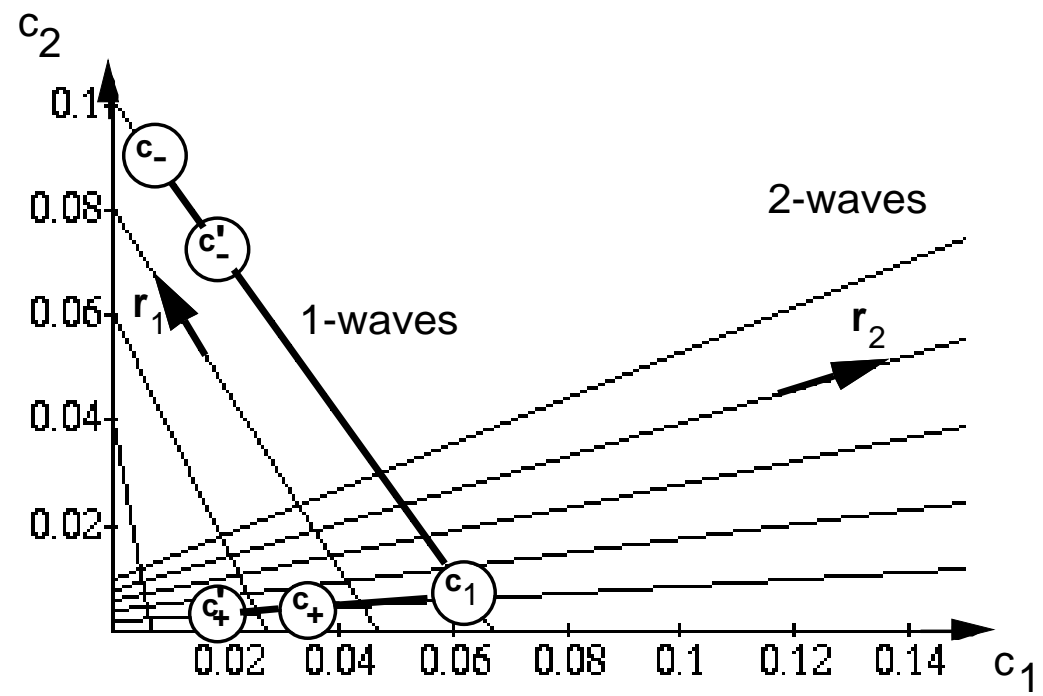

Fig. 7: Two-dimensional concentration space ("composition space") with some 1and 2-waves. Adsorption follows Langmuir isotherm (46). Wave velocity increases in direction of right eigenvector $\mathbf{r}_{\mathrm{k}}$ (see (33)). The solution of the 
Riemann problem is the sequence of constant states $\left(\mathbf{c}_{-} / \mathbf{c}_{1} / \mathbf{c}_{+}\right)$connected by the 1- and 2- waves (heavy lines). According to property (c), $\left(\mathbf{c} *_{-} / \mathbf{c}_{1} / \mathbf{c}_{+}\right)$is a solution of another Riemann problem.

$\mathrm{b}$ has the value 0 or 1 , and the adsorption constants $\mathrm{k}_{\mathrm{j}}^{\alpha}$ are independent from c (see appendix 12 A 3 for proof of the first two properties and figure 7 for an illustration):

(a) The waves (shocks and rarefaction waves) coincide in concentration space.

(b) The waves (shocks or rarefaction waves) are lines (in concentration space).

(c) The waves (shocks or rarefaction waves) are invariant manifolds. This means that the k-wave is represented by the same line independently from its starting point $\mathbf{c}_{\mathrm{k}-1}$ as long as $\mathbf{c}_{\mathrm{k}-1}$ lies on the line.

\subsubsection{Analytical Solution for the Multicomponent System: The Riemann Invariant}

The k-Riemann invariants are functions $\mathrm{w}_{j \neq k}(\mathbf{c})$ of the concentrations and are defined as follows:

$\mathbf{r}_{\mathrm{k}} \operatorname{grad}_{\mathrm{j}}=0 \quad\left(\mathrm{j}=1,2, \ldots, \mathrm{k}-1, \mathrm{k}+1, \ldots, \mathrm{N}_{0}\right)$,

where $\operatorname{grad}=\left\{\partial / \partial \mathrm{c}_{1}, \partial / \partial \mathrm{c}_{2}, \ldots, \partial / \partial \mathrm{c}_{\mathrm{No}_{\mathrm{N}}}\right\}$

Definition (65) means that across a k-wave only $w_{k}$ changes, while the remaining $\mathrm{N}_{0}-1$ invariants $\mathrm{w}_{\mathrm{j} \neq \mathrm{k}}$ are constant. For example, $\mathrm{w}_{1}$ changes only across the 1-wave and remains constant across all subsequent waves. More generally

$\mathrm{w}_{\mathrm{j}}\left(\mathbf{c}_{\mathrm{k}}\right)= \begin{cases}\mathrm{w}_{\mathrm{j}}\left(\mathbf{c}_{+}\right), & (\mathrm{j} \leq \mathrm{k}) \\ \mathrm{w}_{\mathrm{j}}\left(\mathbf{c}_{-}\right), & (\mathrm{j}>\mathrm{k}),\end{cases}$

which means that if all $\mathrm{N}_{0}$ Riemann invariants $\mathrm{w}_{\mathrm{j}}\left(\right.$ with $\mathrm{j}=1,2, \ldots, \mathrm{N}_{0}$ ) are known for the initial and final states, $\mathbf{c}_{+}$and $\mathbf{c}$, they are known for any of the constant states $\mathbf{c}_{\mathrm{k}}$. 
Because $\mathrm{w}_{\mathrm{k}}$ changes only across the $\mathrm{k}$-wave, $\mathrm{w}_{\mathrm{k}}$ can be visualized as a generalized chemical component. If the components did not interact on the adsorbing surfaces, the k-Riemann invariant were identical with the kth chemical components. The initial discontinuity $\mathbf{c}_{+} \rightarrow$ c - would develop with time into a series of waves, one for each component, each experiencing its own retardation. Across each wave only one component would change, all others remaining constant (see figure 1a). Similarly, in the case of interacting components (see figure 1b), each wave experiences its own retardation, and across each wave only one Riemann invariant changes. In their textbook Helfferich and Klein (1970) use the concept of the Riemann invariant, but do not give the invariants this name, calling them $\mathrm{H}$-function roots, instead.

In appendix $12 \mathrm{~A} 3$ it is shown that the waves are (straight) lines if adsorption follows a multicomponent Langmuir isotherm or is an ion exchange process with constant selectivity coefficients. Appendix 12 A. 4 shows that then the scalar product of the left eigenvector of the retardation matrix and the concentration vector is a Riemann invariant

$\mathrm{w}_{\mathrm{j}}\left(\mathbf{c}_{\mathrm{k}}\right)=\mathbf{l}_{\mathbf{j}}\left(\mathbf{c}_{\mathrm{k}}\right) \mathbf{c}_{\mathrm{k}}$,

where the jth left eigenvector (corresponding to eigenvalue $\rho_{j}$ ) for constant state $\mathbf{c}_{\mathrm{k}}$ is defined as

$\mathbf{l}_{j}\left(\mathbf{c}_{\mathrm{k}}\right) \underline{\mathrm{R}}\left(\mathbf{c}_{\mathrm{k}}\right)=\rho_{\mathrm{j}}\left(\mathbf{c}_{\mathrm{k}}\right) \mathbf{I}_{\mathbf{j}}\left(\mathbf{c}_{\mathrm{k}}\right)$.

It is shown in appendix $12 \mathrm{~A} 4$ that all left eigenvectors at any constant state $\mathbf{c}_{\mathrm{k}}$ are known. Introducing a matrix $\underline{\mathrm{L}}$

$\underline{\mathrm{L}}\left(\mathbf{c}_{\mathrm{k}}\right)=\left[\begin{array}{c}\mathbf{1}_{1}\left(\mathbf{c}_{\mathrm{k}}\right) \\ \ldots . \\ \ldots . \\ \mathbf{l}_{\mathrm{N}_{0}}\left(\mathbf{c}_{\mathrm{k}}\right)\end{array}\right]$

the rows of which are the left eigenvectors of the retardation matrix $\underline{\mathrm{R}}\left(\mathbf{c}_{\mathrm{k}}\right)$ and the vector of Riemann invariants

$\mathbf{w}\left(\mathbf{c}_{\mathrm{k}}\right)=\left[\begin{array}{c}\mathrm{w}_{1}\left(\mathbf{c}_{\mathrm{k}}\right) \\ \ldots . \\ \mathrm{w}_{\mathrm{N}_{0}}\left(\mathbf{c}_{\mathrm{k}}\right)\end{array}\right]$, 
we can restate the definition (67) as

$\mathbf{w}\left(\mathbf{c}_{\mathrm{k}}\right)=\underline{\mathrm{L}}\left(\mathbf{c}_{\mathrm{k}}\right) \mathbf{c}_{\mathrm{k}}$.

Because $\mathbf{w}$ and $\underline{L}$ are known, the concentration vectors of the constant states, $\mathbf{c}_{\mathrm{k}}$, can be calculated by inverting (71)

$\mathbf{c}_{\mathrm{k}}=\underline{\mathrm{L}}^{-1}\left(\mathbf{c}_{\mathrm{k}}\right) \mathbf{w}\left(\mathbf{c}_{\mathrm{k}}\right)$.

\section{Waves in Two-Component Systems}

Mass action laws depend non-linearly on the concentrations. In certain restricted areas of concentration space the behavior of a multicomponent system can therefore be interpreted in terms of two-component systems, the contribution of the other components being negligible. Multicomponent transport in porous media might exhibit a similar feature, and therefore thermodynamic adsorption data -although mostly determined in two-component systems- provide helpful, albeit non-complete, information for multicomponent systems. Dzombak and Morel's consistent set of thermodynamic data (1990) describing adsorption of protons and a metal ion on hydrous ferric oxides will be used here as an example.

\subsection{Analytical Solution of the Transport Equations}

The proton concentration $\underline{\mathrm{H}}$ adsorbed on an oxide, e.g. a hydrous ferric oxide, is

$\underline{\mathrm{H}}=2 \mathrm{XOH}_{2}(\mathrm{M}, \mathrm{H})+\mathrm{XOH}(\mathrm{M}, \mathrm{H})$

and the adsorbed metal concentration is

$\underline{\mathrm{M}}=\mathrm{XOM}(\mathrm{M}, \mathrm{H})$,

thus

$\underline{\mathrm{M}}+\underline{\mathrm{H}}=\mathrm{XOM}+2 \mathrm{XOH}_{2}+\mathrm{XOH}$ 
and with $\mathrm{XOH}_{2}=\mathrm{XO}($ see $(59))$

$\underline{\mathrm{M}}+\underline{\mathrm{H}}=\mathrm{XOM}+\mathrm{XOH}_{2}+\mathrm{XOH}+\mathrm{XO}=\mathrm{X}_{\mathrm{T}}$.

To solve the transport equations (7) for the (M-H)-system

$\left(\frac{\mathrm{V}_{\mathrm{w}}}{\phi}-\xi\right) \mathrm{M}^{\prime}-\frac{\xi}{\phi} \underline{\mathrm{M}}^{\prime}=0$

$\left(\frac{\mathrm{V}_{\mathrm{w}}}{\phi}-\xi\right) \mathrm{H}_{\mathrm{t}}^{\prime}-\frac{\xi}{\phi} \underline{\mathrm{H}^{\prime}}=0$

where $\mathrm{H}_{\mathrm{t}}$ is the total proton concentration (see below), we add (77) and (78)

$\left(\frac{\mathrm{V}_{\mathrm{W}}}{\phi}-\xi\right)\left(\mathrm{M}+\mathrm{H}_{\mathrm{t}}\right)^{\prime}-\frac{\xi}{\phi}(\underline{\mathrm{M}}+\underline{\mathrm{H}})^{\prime}=0$

and use the fact that the sum (76) of the adsorbed metal and proton concentrations is constant

$\left(\frac{V_{W}}{\phi}-\xi\right)\left(M+H_{t}\right)^{\prime}=0$

There are two solutions of (80):

$\left(\mathrm{M}+\mathrm{H}_{\mathrm{t}}\right)^{\prime}=0$

and

$\xi=\frac{\mathrm{V}_{\mathrm{w}}}{\phi}$

After using (82) in (62) we know that the adsorbed metal concentration does not change across this non-retarded wave: XOM' $=0$ or

$\operatorname{XOM}(M, H)=\operatorname{XOM}\left(M_{+}, H_{+}\right)$.

The adsorption isotherm (56) then fixes the relationship between $\mathrm{M}$ and $\mathrm{H}$. With (57), the approximation of $\mathrm{P}$ for pristine water $\left(\mathrm{I} \leq 10^{-4}\right.$ $\mathrm{M})$, the isotherm is (62), thus we get 
$\operatorname{XOM}(M, H)=X_{T} \frac{\alpha \sqrt{\frac{k_{2}}{k_{1}}} \frac{M}{H^{2}}}{\alpha \sqrt{\frac{k_{2}}{k_{1}}} \frac{M}{H^{2}}+\left(1+2 \sqrt{k_{1} k_{2}}\right)}$.

This isotherm meets (83) when

$\mathrm{H}=\mathrm{H}_{+} \sqrt{\frac{\mathrm{M}}{\mathrm{M}_{+}}} \quad$ (2-wave, non-retarded)

Thus, the non-retarded wave is determined by the exchange stoichiometry, the adsorption constants do not enter.

The equation for the other wave -given by equation (81)- involves only soluble species. Equation (81) states that the sum of the soluble concentrations is a conserved quantity, i.e. it does not change across the wave

$\mathrm{M}+\mathrm{H}_{\mathrm{t}}=\mathrm{M}_{-}+\mathrm{H}_{\mathrm{t}-}$.

It is customary in speciation calculations to approximate $\mathrm{H}_{t}$ in pristine water by the difference between the proton and the hydroxyl concentrations, assuming that the concentration of the $\mathrm{H}_{2} \mathrm{O}$ complex remains constant:

$\mathrm{H}_{\mathrm{t}}=\mathrm{H}-\mathrm{OH}=\mathrm{H}-\frac{\mathrm{K}_{\mathrm{w}}}{\mathrm{H}}$,

where $\mathrm{K}_{\mathrm{w}}=10^{-14}(\mathrm{~mol} / \mathrm{L})^{2}$. With (87), equation (86) becomes

$\mathrm{M}=\mathrm{M}_{-}-\left(\mathrm{H}-\mathrm{H}_{-}\right)-\mathrm{K}_{\mathrm{w}}\left(\frac{1}{\mathrm{H}}-\frac{1}{\mathrm{H}_{-}}\right) \quad$ (1-wave, retarded $)$.

Figure 8 shows the grid of 1- and 2-waves, with $\mathrm{M}_{+}=\mathrm{M}_{-}=10^{-9}$ $\mathrm{mol} / \mathrm{L}$ and $\mathrm{H}_{+}=\mathrm{H}_{-}=10^{-4} \mathrm{~mol} / \mathrm{L}, 10^{-5} \mathrm{~mol} / \mathrm{L}, \ldots, 10^{-12} \mathrm{~mol} / \mathrm{L}$. Helfferich (1992) has called it the "street map" of the system, because the only way to get from a state (-) to a state (+) is to first follow the 1wave until (point (1) where) it meets a 2 -wave along which one can get to state $(+)$ (see example in figure 8 ). 


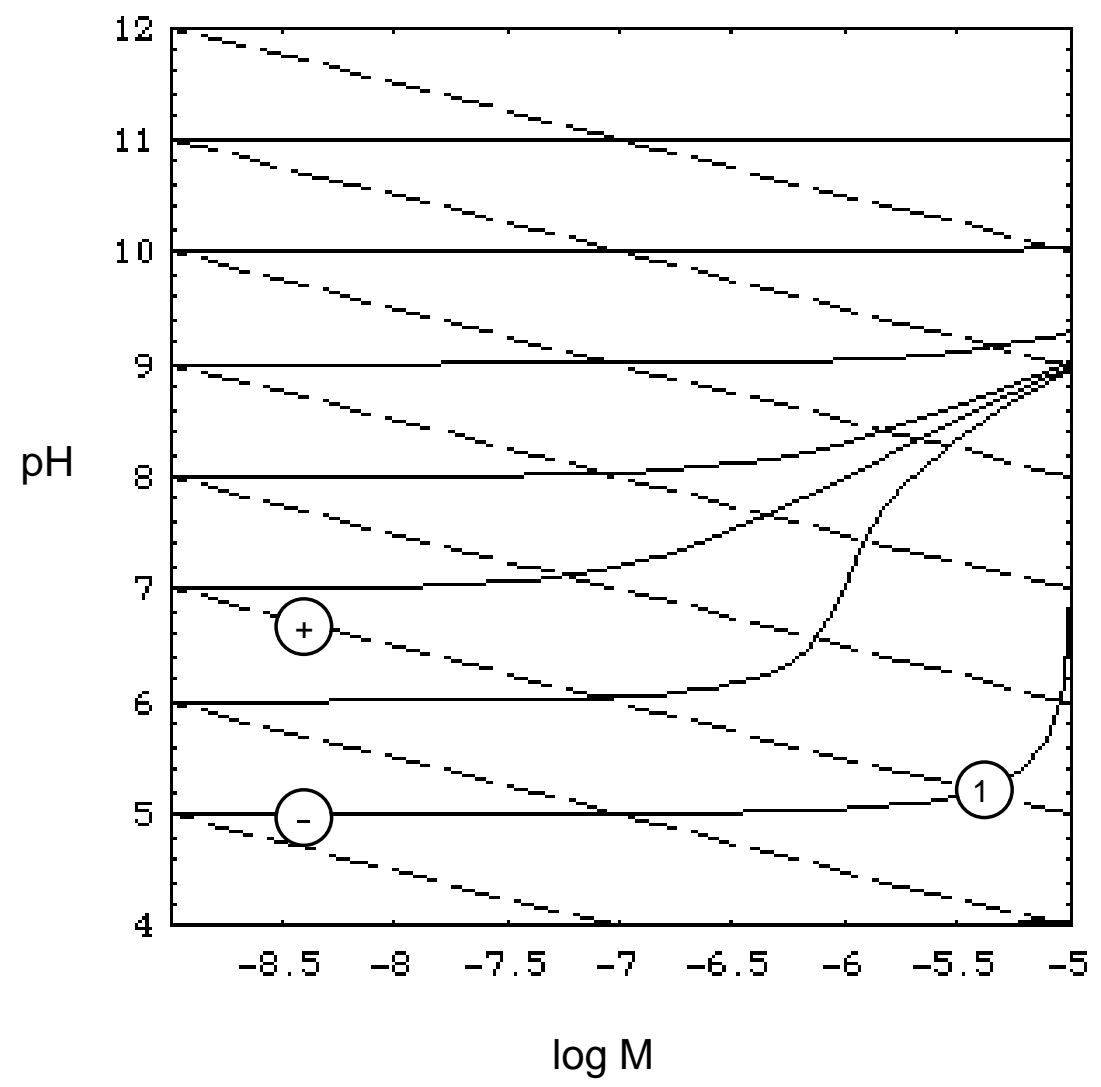

Fig. 8: 1- and 2-waves, (85) and (88), in concentration space. 2-waves are dashed. Units of M: mol/L. The points (-), (1) and (+) mark the solution of a particular Riemann problem. Note that the logarithmic plot exaggerates the angle between the waves at high $\mathrm{pH}$.

The retardation of the 1-wave is $\rho_{1}(\mathrm{M}, \mathrm{H})$, the larger of the two eigenvalues of $\underline{R}(\mathrm{M}, \mathrm{H})$ (see (31)). It has the simple form

$\rho_{1}(\mathbf{c})=1+\frac{1}{\phi} \frac{\partial \mathrm{XOM}(\mathbf{c})}{\partial \mathrm{M}}\left(1+\frac{2 \mathrm{HM}}{\mathrm{H}^{2}+\mathrm{K}_{\mathrm{w}}}\right)$

with

$\frac{\partial \mathrm{XOM}(\mathbf{c})}{\partial \mathrm{M}}=\mathrm{X}_{\mathrm{T}} \frac{\alpha \mathrm{PZC}\left(1+2 \mathrm{k}_{1} \mathrm{PZC}\right) \mathrm{H}^{2}}{\left(\alpha \mathrm{PZC} \mathrm{M}+\mathrm{H}^{2}\left(1+2 \mathrm{k}_{1} \mathrm{PZC}\right)\right)^{2}}$. 
At low ionic strength the surface charge on the oxide is small, and therefore approximation (57) could be used to calculate a solution of the transport equations (77) and (78).

It is interesting to notice the similarity between the oxde system at low ionic strength and an ion exchange system with constant surface charge. For a two-component system $\left(\mathrm{N}_{0}=2\right)$ with an exchange isotherm (41), the analytical solution method gives for the 1- and 2waves $\left(\mathrm{c}_{1}+\mathrm{c}_{2}\right)^{\prime}=0$ and $\xi=\mathrm{v}_{\mathrm{w}} / \phi$, respectively, or

$\mathrm{c}_{1}+\mathrm{c}_{2}=\left(\mathrm{c}_{1}\right)+\left(\mathrm{c}_{2}\right)$

i.e

$c_{2}=-c_{1}+\left(c_{1}\right)_{-}+\left(c_{2}\right)_{-} \quad(1-$ wave, retarded $)$,

as compared to (88).

From $\mathrm{C}_{\mathrm{j}}{ }^{*}\left(\mathrm{c}_{1}, \mathrm{c}_{2}\right)=\mathrm{C}_{\mathrm{j}}{ }^{*}\left(\left(\mathrm{c}_{1}\right)_{+},\left(\mathrm{c}_{2}\right)_{+}\right)$follows for the isotherm (41)

$\mathrm{c}_{2}=\left(\mathrm{c}_{2}\right)_{+} \frac{\mathrm{c}_{1}}{\left(\mathrm{c}_{1}\right)_{+}} \quad$ (2-wave, non-retarded $)$

as compared to (85).

The independence of the shape of those waves (91) and (92) from the concentrations $\mathbf{c}_{-}$and $\mathbf{c}_{+}$and the separation factor $\alpha_{12}$ is peculiar to the exchange (35) in a system with only 2-components.

Contrary to the shape of the waves, the retardation of the 1-wave, i.e. the eigenvalue $\rho_{1}\left(c_{1}, c_{2}\right)$ of $\underline{R}\left(c_{1}, c_{2}\right)$, depends on the identity of the exchanging ions. As compared to (89) and (90) it is a simpler function of the separation factors and concentrations

$\rho_{1}=1+\frac{X_{\mathrm{T}}}{\phi} \frac{\alpha_{12}\left(\mathrm{c}_{1}+\mathrm{c}_{2}\right)}{\left(\alpha_{12} \mathrm{c}_{1}+\mathrm{c}_{2}\right)^{2}}$

\subsection{Exchange Systems with Buffers}

Both waves will be retarded whenever there is a "buffer" in the system that allows adsorption to break away from the rigid one-toone exchange depicted in figure 4 or expressed in (81) as a consequence of (57), or (91). We have such a buffered situation when 
(1) the two components adsorb according to a Langmuir isotherm (46) on constant charge surfaces $(P=1)$, the empty sites playing the role of the buffer,

(2) we have three species and

(a) one of the species concentrations in solution is constant (isotherm (46)) or

(b) the sum of the species concentrations in solution is constant (isotherm (48)).

The initial discontinuity $\mathbf{c}_{+} \rightarrow \mathbf{c}_{-}$of the Riemann problem develops into a sequence of two retarded waves, a slow one, the 1-wave, and a fast one, the 2-wave. In composition space these waves are lines tangential to a parabola (Helfferich and Klein, 1970; Rhee et al., 1989), as depicted in figure 9. The proof can be found in appendix 12 A. 4 . The equation of the parabola is

$\overline{\mathrm{c}}_{2}=1-\overline{\mathrm{c}}_{1} \pm 2 \sqrt{-\overline{\mathrm{c}}_{1}}$, with $\overline{\mathrm{c}}_{\mathrm{j}}=\frac{\mathrm{c}_{\mathrm{j}}}{\mathrm{k}}$

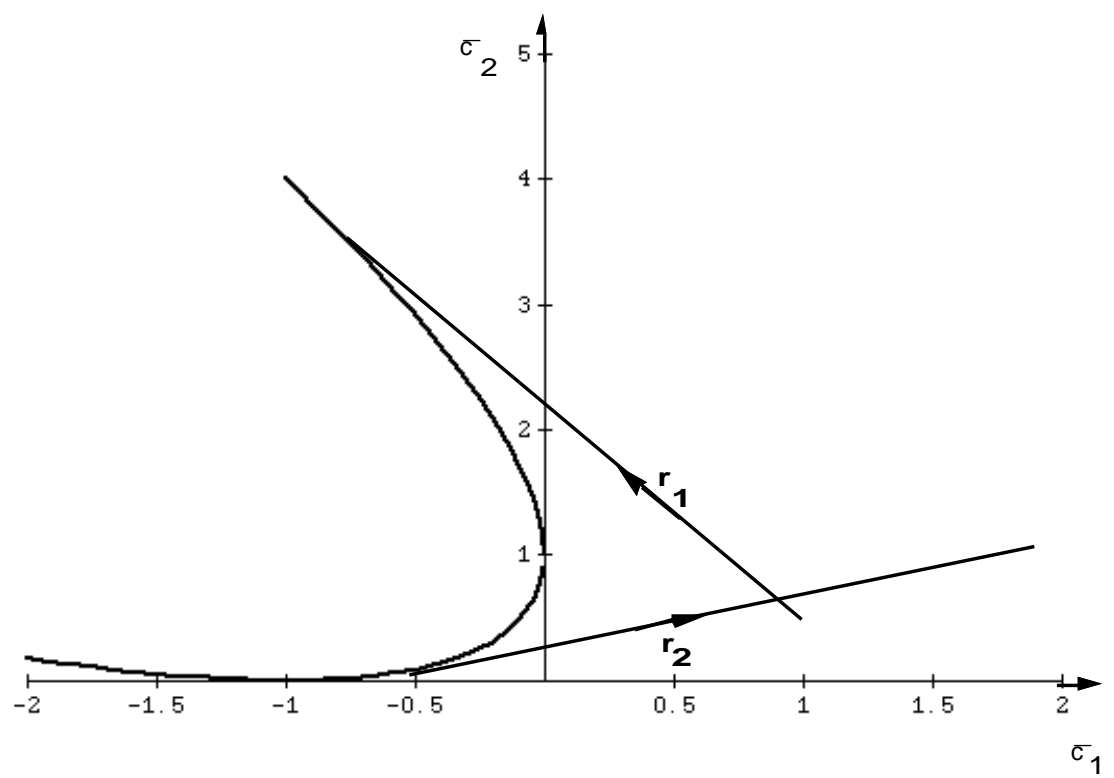

Fig. 9: Parabola (94) with waves. $\mathbf{r}_{1}$ and $\mathbf{r}_{2}$ are the right eigenvectors parallel to the 1- and 2-wave, respectively.

The value of $\mathrm{k}$ depends on the form of the isotherm. In the exchange system (case 2b, in which all three concentrations may vary 
under the constraint $\mathrm{c}_{1}+\mathrm{c}_{2}+\mathrm{c}_{3}=\mathrm{c}(\mathrm{c}=$ constant, including $\left.\mathrm{c}=0)\right)$, i.e. for

$C_{j}^{*}(\mathbf{c})=X_{T} \frac{\alpha_{j 3} c_{j}}{\alpha_{13} c_{1}+\alpha_{23} c_{2}+c_{3}} \quad\left(j=1,2,3\right.$ and $\left.\sum_{i=1}^{3} c_{i}=c\right)$

we get

$\mathrm{k}=\frac{1-\alpha_{12}}{\alpha_{13}-1} \mathrm{c}$.

For a system with surface bridge formation or an exchange system with constant $c_{3}$ (in the latter we introduce $\mathrm{k}_{\mathrm{j}}=\alpha_{\mathrm{j} 3} / \mathrm{c}_{3}$ ), i.e. for

$\mathrm{C}_{\mathrm{j}}^{*}(\mathbf{c})=\mathrm{X}_{\mathrm{T}} \frac{\mathrm{k}_{\mathrm{j}} \mathrm{c}_{\mathrm{j}}}{1+\mathrm{k}_{1} \mathrm{c}_{1}+\mathrm{k}_{2} \mathrm{c}_{2}} \quad(\mathrm{j}=1,2)$

we get

$\mathrm{k}=\frac{1}{\mathrm{k}_{1}}-\frac{1}{\mathrm{k}_{2}}$

The parabola lies in the upper left quadrant when $\mathrm{k}$ is positive, and in the lower right quadrant when $\mathrm{k}$ is negative. The buffer disappears when $\mathrm{k} \rightarrow 0$, which is equivalent to an isotherm (41) with $\mathrm{N}_{0}=2$,

$\mathrm{C}_{\mathrm{j}}^{*}(\mathbf{c})=\mathrm{X}_{\mathrm{T}} \frac{\alpha_{\mathrm{j} 2} \mathrm{c}_{\mathrm{j}}}{\alpha_{12} \mathrm{c}_{1}+\mathrm{c}_{2}} \quad(\mathrm{j}=1,2)$.

For the 2-component system with bridge formation, (97), we get for the retardations of the 1- and 2-wave

$\rho_{1,2}=1+\frac{\mathrm{X}_{\mathrm{T}}}{2}\left\{\frac{\mathrm{k}_{1}\left(1+\mathrm{k}_{2}\left(\mathrm{c}_{1}+\mathrm{c}_{2}\right)\right)+\mathrm{k}_{2}}{\delta^{2}} \pm \sqrt{\frac{\mathrm{k}_{1}\left(1+\mathrm{k}_{2}\left(\mathrm{c}_{1}+\mathrm{c}_{2}\right)\right)+\mathrm{k}_{2}^{2}}{\delta^{2}}-\frac{4 \mathrm{k}_{1} \mathrm{k}_{2}}{\delta^{3}}}\right\}$

with

$\delta=1+\mathrm{k}_{1} \mathrm{c}_{1}+\mathrm{k}_{2} \mathrm{c}_{2}$

When $c_{2} \gg \mathrm{k}$, the 1-waves in the 2-component system with bridge formation approach asymptotically the 1-waves (91) of the 2component exchange system (41). At these elevated concentrations almost all surface sites (in the system with surface bridges) are oc- 
cupied by either species $A_{1}$ or $A_{2}$, and the adsorption process degenerates into an exchange between these two species. This explains the asymptotic slope -1 of the 1 -waves in figure. 9.

\section{Barrier Against Remobilization of a Contaminant}

From (93) one can see that in a Langmuir or ion exchange system with two independent components $\mathrm{A}_{1}$ and $\mathrm{A}_{2}$

(1) the slope of the 1-wave approaches -1 as $c_{2-}>>k$,

(2) the slope of the 2-wave approaches 0 as $c_{2+}<<$,

if $\mathrm{k}$ is positive, i.e. component $\mathrm{A}_{2}$ adsorbs more strongly $\left(\alpha_{12}<1\right.$ or $\mathrm{k}_{1}<\mathrm{k}_{2}$ ). Assume that the other component, $\mathrm{A}_{1}$, is a contaminant.

Figure 10 displays the failure of the adsorption barrier: Initially, the contaminant inventory is adsorbed on the soil particles $\left(c_{1+} \approx 0\right)$. When the concentration of the other component in the feed is raised above the threshold $\mathrm{k}$, the contaminant is removed from the adsorbing sites and its inventory is carried between the waves. The contaminant concentration $\mathrm{c}_{11}$ between the waves is of the same order of magnitude as the concentration of the remobilizing solute in the feed $\left(c_{11} \approx c_{2}\right)$, because the slopes of the 1- and 2-waves are approximately -1 and 0 , respectively. 


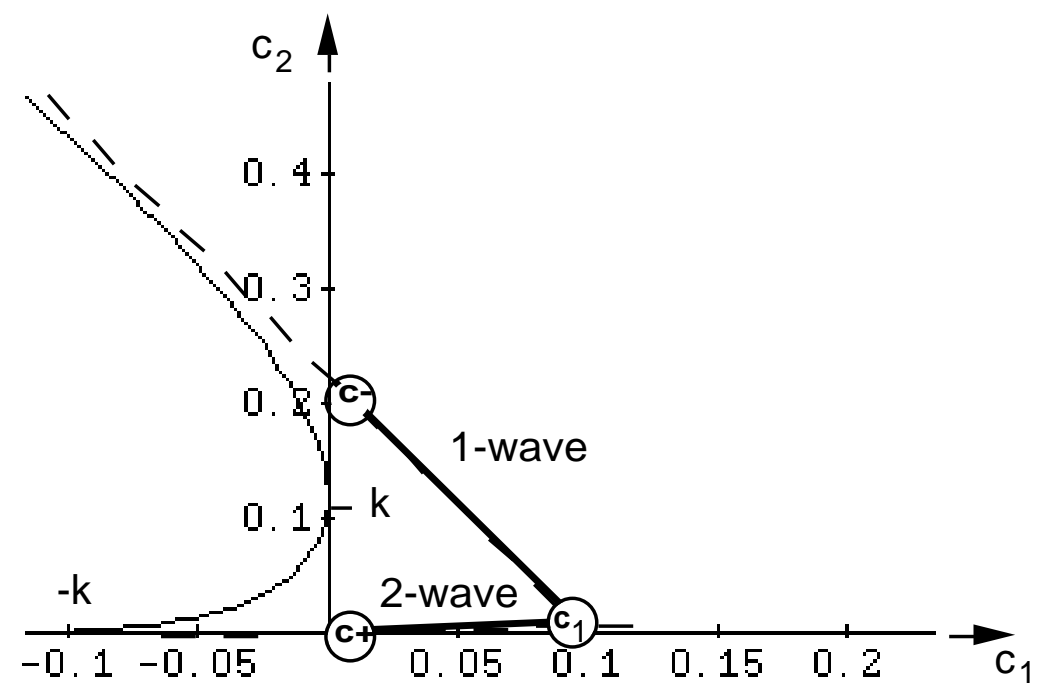

Fig. 10: Parabola (93) and waves in a system with two components. Isotherm: Langmuir type (97), $\mathrm{k}_{1}=5.0 \mathrm{M}^{-1}, \mathrm{k}_{2}=12.0 \mathrm{M}^{-1}$. Component $\mathrm{A}_{1}$ : contaminant, component $\mathrm{A}_{2}$ : remobilizing agent.

Figure 11 shows the spatial variation of the corresponding concentration profiles, $c_{i}(x, t)$. The described adsorption barrier (97) will not fail when the contaminant is bound more strongly to the adsorbing surfaces than the competing species, $A_{2}$, i.e. when $\alpha_{12}>1$ or $k_{1}>$ $\mathrm{k}_{2}$ (see figure 12).

Whereas the 1-waves are not changed as compared to the case shown in figure 10 and 11, the slope of the 2-waves does not approach 0 as $\mathbf{c}_{+}$approaches 0 . Therefore the concentration of the contaminant between the waves cannot raise much above the one prior to remobilization. 

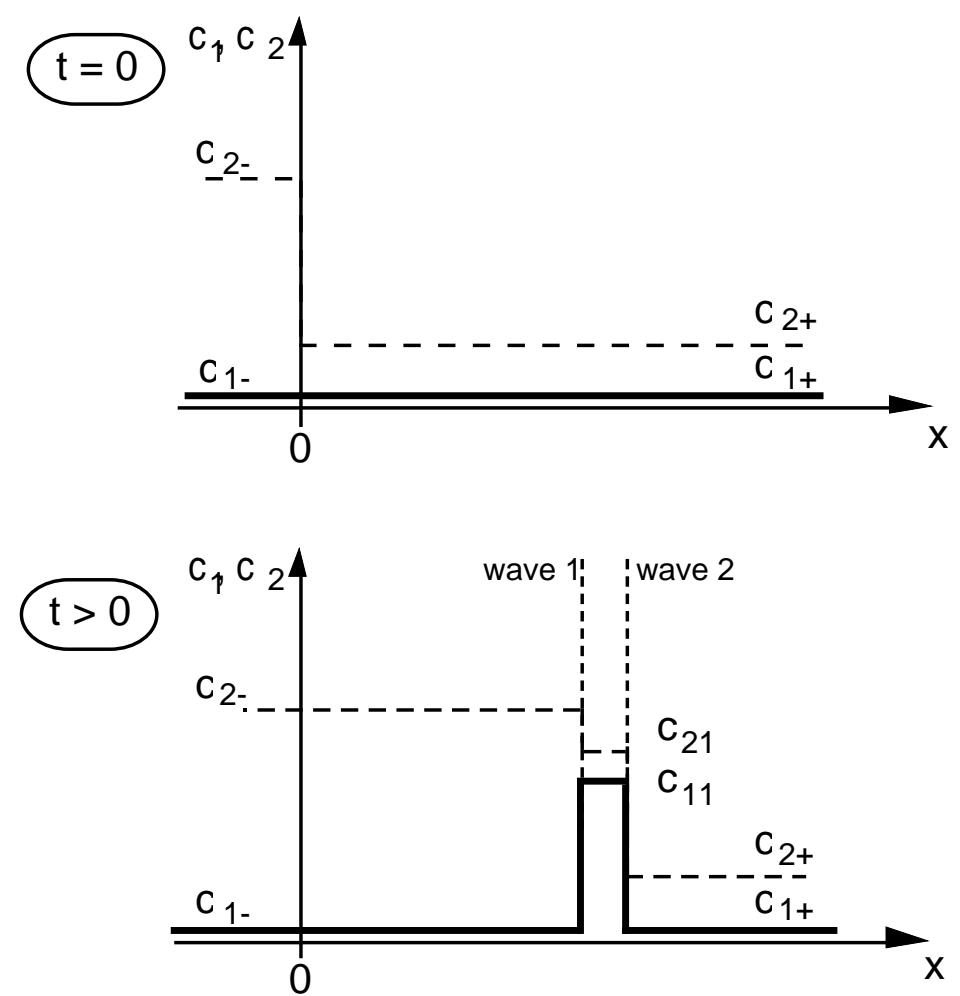

Fig. 11: Failure of adsorption barrier. $A_{1}$ is contaminant, $A_{2}$ remobilizing agent.

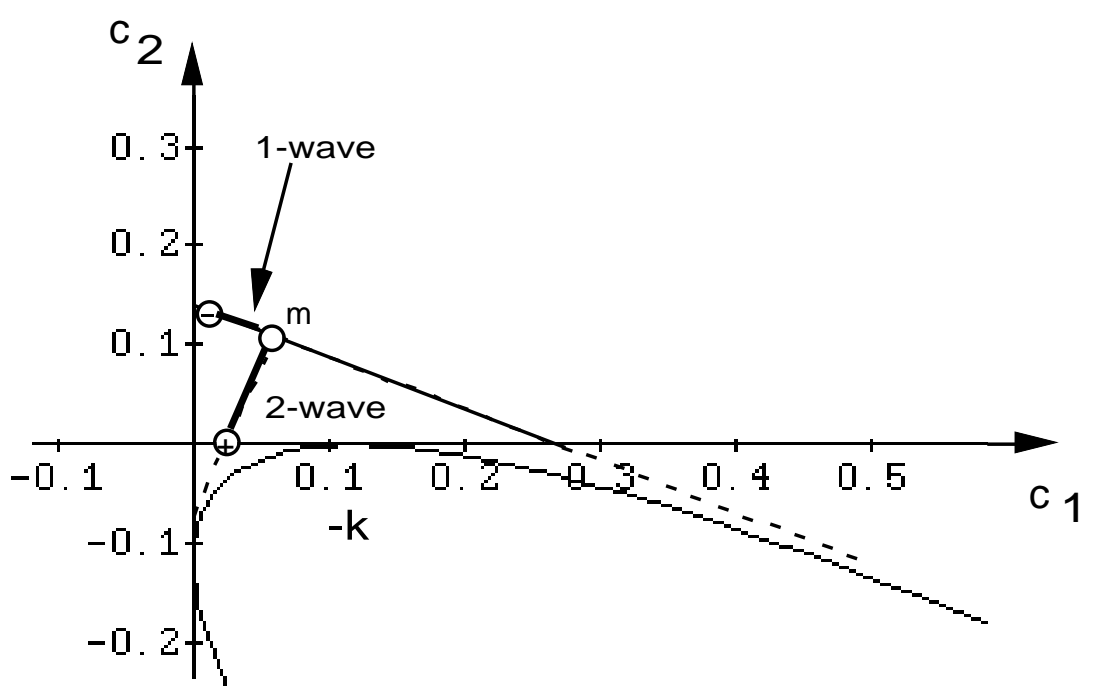

Fig. 12: An adsorption barrier that cannot fail: $\mathrm{k}<0$. Component $\mathrm{A}_{1}$ : contaminant, component $\mathrm{A}_{2}$ : remobilizing agent. 
The described effect has been applied in various areas to purify materials from unwanted components: Pfann (1958) has introduced the zone melting process to remove impurities from semiconductor materials. A heat wave (instead of a wave of a competing species) is remobilizing the impurity atoms. A similar process (using steam) has been proposed by Hunt (1988) to remove gasoline trapped in soils. Harwell (1992) discussed remobilizing such non aqueous phase liquids with a chlorinated hydrocarbon solvent or surfactant wave.

\section{Conclusions}

A single abrupt change of the water composition at the inlet of a column of a porous medium with a homogeneous concentration distribution develops with time into a series of centered waves, if hydrodynamic dispersion is neglected. Centered waves are thus a class of solutions of the chromatographic transport equations that can be considered the basic building blocks of general solutions. There are as many centered waves as there are chemical components in the system.

It is customary and helpful in chromatography to plot the variation of the concentration vector across a wave in concentration space. When this is done for a set of waves, a net of curves results which Helfferich has called the "Street Map of the System". It is characteristic for the chemical interactions in solution and on the adsorbing surfaces. Its computation does not exceed the limitations imposed on an experimental laboratory. It requires similar capacities as equilibrium speciation calculations which are now standard tools in such labs.

Because of the mentioned chemical non-linearities, thresholds run through concentration space at which the net of waves changes shape. Experience we gained on one side of a threshold is irrelevant beyond it. Once the net of centered waves is known for a set of thermodynamic parameters, the influence of parameter variations can be interpreted in terms of its deformations and the change of the threshold locations.

This helps to understand the impact of uncertainties in the chemical interactions more comprehensively than results of standard nu- 
merical models, e.g. of coupled finite-difference chemical-speciation models. The latter compute waves for initial and boundary conditions that are discrete, isolated points in concentration space. Since they do not reveal the general structure of the waves such as the locations of the thresholds, neither inter- nor extraplolation of numerical results is justified without prior knowledge of the thresholds.

The results of chromatographic calculations are thus useful guides for design and interpretation of numerical computations as well as chemical experiments assessing the adequacy of the assumed chemical interactions. When the character of e.g. the chemical barriers against remobilization has been clarified in feedback between experiment and chromatographic model computations, follow-up numerical calculations can concentrate on site specific critical problems.

\section{Acknowledgement}

Part of this research was done while the author was visiting member of the Courant Institute for Mathematical Sciences of New York University, New York. Without the long discussions with F. Helfferich of The Pennsylvania State University this work would not have been possible.

\section{Appendices}

\section{A.1 Relative Influence of Diffusion/Dispersion and First Order Kinetics in a Single-Component System}

For a system (1) and (2) with only one component adsorbing

$\frac{\partial}{\partial t}(\phi c(x, t)+C(x, t))+\frac{\partial}{\partial x}\left(v_{w}-D \frac{\partial}{\partial x}\right) c(x, t)=0$

$\frac{\partial \mathrm{C}(\mathrm{x}, \mathrm{t})}{\partial \mathrm{t}}=\frac{\mathrm{C}^{*}(\mathrm{c})-\mathrm{C}(\mathrm{x}, \mathrm{t})}{\varepsilon}$

it can be shown (Liu, 1987, see also section 12A. 2) that the solution of the Riemann problem with $\mathbf{c}_{-}>\mathbf{c}_{+}$is for large $\mathrm{t}(\mathrm{t}->\infty)$ 
(*) a traveling wave $c_{\infty}(x, t)$ for $\mathrm{D}=0$

$c_{\infty}(x, t)=c(s)$

with

$$
\begin{aligned}
& \mathrm{s}=\mathrm{x}-\sigma \mathrm{t}, \\
& \sigma=\frac{\mathrm{V}_{\mathrm{w}}}{\phi \mathrm{R}}, \\
& \mathrm{R}=1+\frac{1 \mathrm{C}^{*}\left(\mathrm{c}_{+}\right)-\mathrm{C}^{*}\left(\mathrm{c}_{-}\right)}{\phi \quad \mathrm{c}_{+}-\mathrm{C}_{-}}
\end{aligned}
$$

-the latter given by the Rankine-Hugoniot relation (24).

Thus, the concentration jump (4) develops into a steady profile $\mathrm{c}(\mathrm{s})$ when we wait long enough.

With (A 1. 3) the time asymptotic transport equation is with d/ds abreviated as '

$$
\frac{d}{d s}\left[-\sigma\left(\phi c+C^{*}\right)+v_{w} c-2 \sigma^{2} \varepsilon C^{* \prime} c^{\prime}\right]=0 .
$$

(*) the same traveling wave (A 1.3) for $\varepsilon=0$ or $\mathrm{C}=\mathrm{C}^{*}$.

With (A 1.3) the time asymptotic transport equation is with d/ds abreviated as '

$$
\frac{d}{d s}\left[-\sigma\left(\phi c+C^{*}\right)+v_{w} c-D c^{\prime}\right]=0
$$

The interpretation of the development of a traveling wave is this: Dispersion or adsorption kinetics tend to produce a smooth transition between $\mathrm{c}_{+}$and $\mathrm{c}_{-}$, whereas the nonlinear dependence of the adsorbed concentration $\mathrm{C}^{*}$ on c counteracts dispersion or kinetics and tries to produce a steep profile. The traveling wave is the stationary compromise. 
It is assumed that also for $\mathrm{D} \neq 0$ the transport equations (A 1. 1) and (A 1.2) have a traveling wave as time asymptotic solution, and that its width is given by the dispersion process if

$2 \sigma^{2} \varepsilon C^{* \prime}<\mathrm{D}$.

Using the definitions (A 1.5) and (A 1.6) and the separation of the dispersion into diffusion and hydrodynamic dispersion

$\mathrm{D}=\mathrm{D}^{*} \tau+\delta \frac{\mathrm{V}_{\mathrm{W}}}{\phi}$

where $D^{*}$ is the diffusion coefficient in water, $\tau$ the tortuosity $(0.3), \delta$ the dispersivity,

and the approximation

$\mathrm{C}^{* \prime}=\phi(\mathrm{R}-1)$

the upper limit of $\varepsilon$ after (A 1.9) can be written as

$\varepsilon=\frac{\mathrm{R}^{2} \phi}{2 \mathrm{v}_{\mathrm{w}}^{2}(\mathrm{R}-1)} \mathrm{D}=\frac{\mathrm{R}^{2} \phi}{2 \mathrm{v}_{\mathrm{w}}^{2}(\mathrm{R}-1)}\left(\mathrm{D} * \tau+\frac{\delta \mathrm{v}_{\mathrm{w}}}{\phi}\right)=10.5 \frac{\mathrm{R}^{2}}{\mathrm{R}-1}$ days

The right hand side of (A 1. 12) has been evaluated for $\phi=\tau=0.3, \delta$ $=0, \mathrm{D}^{*}=0.16 \mathrm{~m}^{2} / \mathrm{yr}$ and $\mathrm{v}_{\mathrm{w}}=0.5 \mathrm{~m} / \mathrm{yr}$.

The interpretation of (A 1. 12) is this: If the adsorbed concentration $\mathrm{C}$ reaches $37 \%$ of its equilibrium value, i.e. $\mathrm{C} * / \mathrm{e}(\mathrm{e}=2.71)$, within a period $\varepsilon$ or less, the kinetics of the adsorption process has a negligible influence -as compared to diffusion/dispersion- on the shape of the traveling wave.

Figure A 1. shows more detail of (A 1. 12) by demonstrating how the upper limit of $\varepsilon$ depends on the speed $\mathrm{v}_{\mathrm{W}}$ of the water, two retardations $(\mathrm{R}=5$ and 1.1$)$ and various dispersivities $\delta$, the latter being approximated by $\mathrm{L} / 100$. 

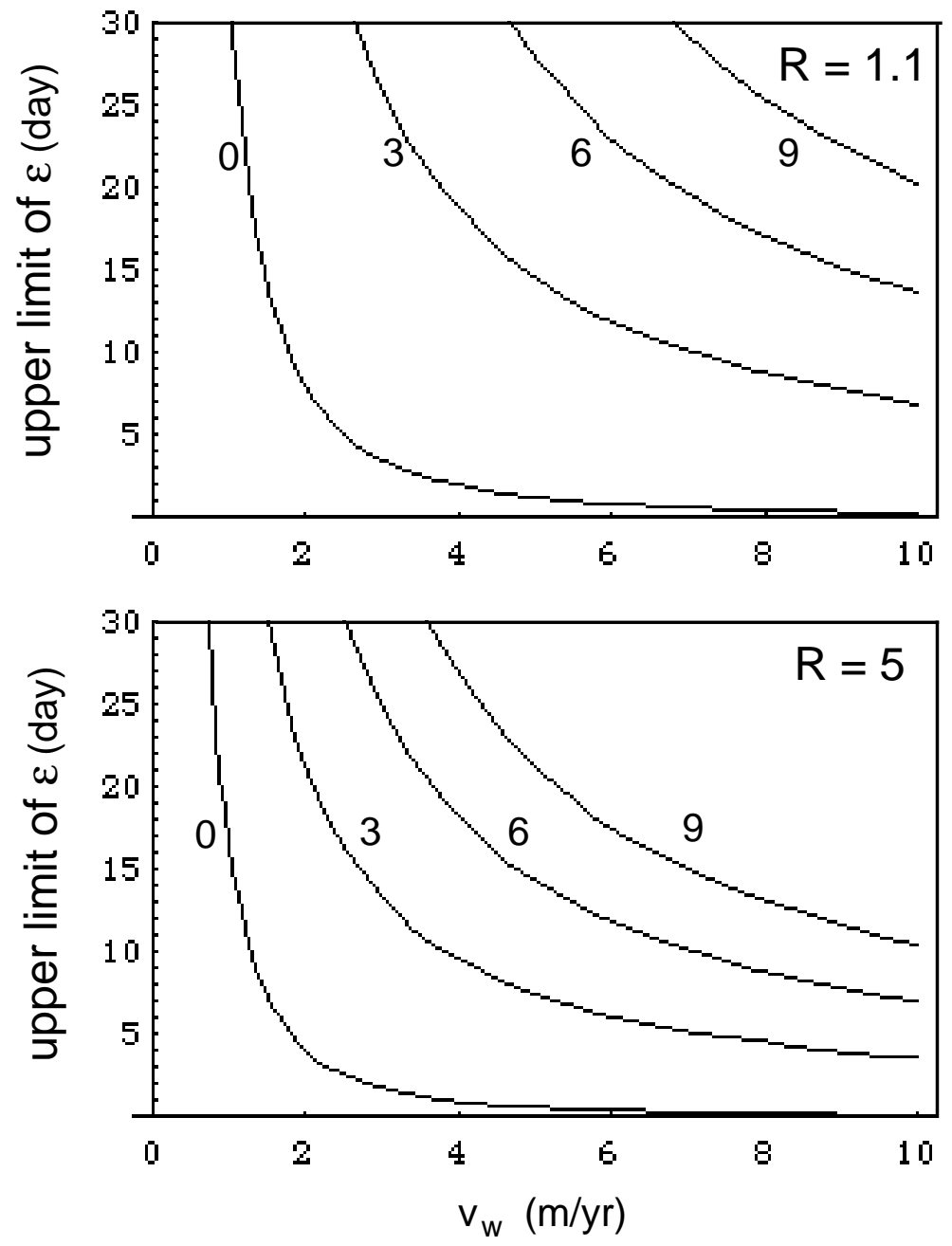

Fig. A 1: Upper limit of relaxation time $\varepsilon$, (A 1. 12), as a function of speed $v_{\mathrm{W}}$ of water for $\mathrm{L}=0,3,6$ and $9 \mathrm{~m}$. $\delta=0.01 \mathrm{~L}$ has been used.

To get an analytical expression for the influence of relaxation relative to dispersion, let us consider a moderately retarded species (e.g. $\mathrm{R}>5$ ), so that we can neglect the 1 in the denominator of (A 1. 12). After multiplying both sides of (A 1. 12) with $\sigma^{2} \varepsilon=\left(\mathrm{V}_{\mathrm{w}} /(\phi R)\right)^{2} \varepsilon$ and taking the square root of both sides

$\sigma \varepsilon<\frac{1}{\sqrt{2}} \sqrt{\frac{\mathrm{D}}{\phi(\mathrm{R}-1)} \varepsilon}=\frac{1}{\sqrt{2}} \sqrt{\widetilde{\mathrm{D}} \varepsilon}$. 
where $\widetilde{D}=\mathrm{D} /(\phi(\mathrm{R}-1))$ approaches the retarded dispersion coefficient, $\mathrm{D} /(\phi \mathrm{R})$, for large $\mathrm{R}$.

Equation (A 1. 13) compares two lengths calculated in two different one-component systems:

Left side: Assume a purely advective system at equilibrium (equation (1) with $\mathrm{C}=\mathrm{C}^{*}$ and $\mathrm{D}=0$ ). $\sigma \varepsilon$ is the advective distance a wave travels during the relaxation time $\varepsilon$ (advection during relaxation).

Right side: Assume a purely dispersive system at equilibrium (equation (1) with $\mathrm{C}=\mathrm{C}^{*}$ and $\left.\mathrm{v}_{\mathrm{w}}=0\right) \cdot \sqrt{ }(\widetilde{\mathrm{D} \varepsilon})$ is the width of the profile $\mathrm{c}(\mathrm{x}, \mathrm{t}=\varepsilon)$ for an initial concentration jump $(\mathrm{c}(\mathrm{x}, 0)$ $=\mathrm{c}_{-}$for $\mathrm{x}<0$ and $\mathrm{c}_{+}$for $\mathrm{x} \geq 0$ ).

In this sense relaxation of adsorption can be neglected against dispersion if advection during relaxation $(\sigma \varepsilon)$ is smaller than the width of the profile $\sqrt{ }(\widetilde{D} \varepsilon)$ divided by $\sqrt{ } 2$.

Evaluated for natural water flow $\left(\mathrm{v}_{\mathrm{w}}<0.5 \mathrm{~m} / \mathrm{yr}\right)$ through river or lake sediments in moderate latidudes (A 1. 12) means: Relaxation times $\varepsilon<1$ week have a negligible influence on the shape of naturally produced profiles (see also the very comprehensive analysis of van der Zee (1990)).

\section{A.2 Non-Linear Single-Component Transport: 12 A.2.1 Non-Equilibrium Transport without Diffusion}

The transport equation for a single component without diffusion is the conservation law (A 2. 1)

$\frac{\partial c}{\partial x}+\frac{1}{v_{w}} \frac{\partial}{\partial t}(\phi c+C)=0$

where

$\frac{\partial \mathrm{C}}{\partial \mathrm{t}}=\frac{\mathrm{C}^{*}-\mathrm{C}}{\varepsilon}$ 
$\mathrm{c}$ and $\mathrm{C}$ are the species concentrations in the soluble phase and on the adsorbing soil surfaces, respectively. The soil consists of the soluble phase (water) and the solid phase (soil particles), the volume fractions of which are $\phi$ and $1-\phi$, respectively. $v_{w}$ is the flux of the water. $\phi$ and $\mathrm{v}_{\mathrm{w}}$ are constants. The adsorbed concentration $\mathrm{C}(\mathrm{x}, \mathrm{t})$ relaxes to its equilibrium value $\mathrm{C}^{*}$ (c). $\varepsilon$ is the corresponding relaxation time due to adsorption kinetics.

Liu (1987) presented a solution for (A 2. 1), (A 2. 2) for the Riemann problem :

This system (A 2. 1), (A 2. 2) has the characteristics $1_{1}=0$ and $l_{2}=$ $\mathrm{v}_{\mathrm{W}} / \phi$. The equilibrium characteristic $1^{*}$, i.e. the one for (A 2. 1)) with $\mathrm{C}=\mathrm{C}^{*}$, is

$\lambda^{*}=\frac{\mathrm{v}_{\mathrm{W}}}{\phi} \frac{1}{1+\frac{1}{\phi} \frac{\mathrm{dC^{* } ( \mathrm { c } )}}{\mathrm{dc}}}=\frac{\mathrm{v}_{\mathrm{W}}}{\phi} \frac{1}{1+\frac{\mathrm{X}_{\mathrm{T}}}{\phi} \frac{\mathrm{k}}{(1+\mathrm{kc})^{2}}}$

Thus, $1^{*}$ is a subcharacteristic $\left(l_{1}<1^{*}<1_{2}\right)$. by

The system (A 2. 1), (A 2. 2) can be asymptotically approximated

$\frac{\partial c}{\partial x}+\frac{1}{v_{w}} \frac{\partial}{\partial t}\left(\phi c+C^{*}\right)-\left(\frac{\partial}{\partial t} \beta(c) \frac{\partial c}{\partial t}\right)=0$

where

$\beta(c)=\frac{2 \varepsilon}{V_{\mathrm{w}}} \frac{\mathrm{d} \mathrm{C}^{*}(\mathrm{c})}{\mathrm{dc}}$.

Liu shows that a traveling wave

$\mathrm{c}(\mathrm{x}, \mathrm{t})=\mathrm{c}(\mathrm{x}-\sigma \mathrm{t})=\mathrm{c}(\mathrm{s})$

is a solution of (A 2. 1), (A 2. 2) for the Riemann problem (with $\mathrm{c}_{+}$ and $\mathrm{c}_{-}$being the concentrations right and left of the discontinuity, respectively). $\sigma$ is given by the Rankine-Hugoniot condition (24) for the equilibrium system $\left(\mathrm{C}=\mathrm{C}^{*}\right)$ 
$\sigma=\frac{\mathrm{V}_{\mathrm{w}}}{\phi} \frac{\Delta \mathrm{c}}{\Delta\left(\mathrm{c}+\frac{1}{\phi} \mathrm{C}^{*}\right)}=\frac{\mathrm{V}_{\mathrm{w}}}{\phi} \frac{1}{1+\frac{1}{\phi} \frac{\Delta \mathrm{C}^{*}}{\Delta \mathrm{c}}}=\frac{\mathrm{V}_{\mathrm{W}}}{\phi} \frac{1}{\mathrm{R}}$,

with $\Delta \mathrm{c}=\mathrm{c}_{+}-\mathrm{c}_{-}, \Delta\left(\mathrm{C}^{*}\right)=\left(\mathrm{C}^{*}\left(\mathrm{c}_{+}\right)\right)-\left(\mathrm{C}^{*}\left(\mathrm{c}_{-}\right)\right)$.

Using (A 2.6) in (A 2. 4), we can integrate the transport equation to get the profile $\mathrm{s}(\mathrm{c})$ of the traveling wave. With the abbreviations

$\widehat{\mathrm{c}}=\frac{\mathrm{c}-\mathrm{c}_{+}}{\Delta \mathrm{c}}, \widehat{C}^{*}=\frac{\mathrm{C}^{*}-\mathrm{C}_{+}^{*}}{\Delta \mathrm{C}^{*}}$

the result is (for proof see paragraph IV below)

$\int_{c_{+}}^{c} \frac{d s}{d c} d c=s(c)-s\left(c_{+}\right)=\frac{2 \sigma^{2} \varepsilon}{v_{w}\left(1-\frac{1}{R}\right)} \int_{c_{+}}^{c} \frac{C^{* \prime} d \hat{c}-\widehat{C}^{*}}{.}$.

\section{A.2.2 Equilibrium Transport with Diffusion}

When diffusion is included, the transport equation for a single component in local equilibrium with the soil surfaces is

$\frac{\partial}{\partial t}\left(\phi c+C^{*}\right)+\frac{\partial}{\partial x}\left(v_{w}-D \frac{\partial}{\partial x}\right) c=0$

Limiting ourselves again to the asymptotic solution, the traveling wave (A 2. 6), (A 2. 9) can be integrated resulting in the following equation for the profile

$s(c)-s\left(c_{+}\right)=\frac{D}{v_{w}\left(1-\frac{1}{R}\right)} \int_{c_{+}}^{c} \frac{d \hat{c}-\widehat{C}}{C^{*}}$,

For the Langmuir isotherm, Lake and Helfferich (1978) and van der Zee (1988) derived an analytical expression for the integral in (A 2. 10). Later (1990), van der Zee derived an analytical expression for the case of combined non-equilibrium and diffusion/dispersion. 


\section{A.2.3 Linear Transport of a Single Component}

If the adsorption isotherm is linear

$\mathrm{C}^{*}(\mathrm{c})=\phi(\mathrm{R}-1) \mathrm{c}$

the solution of the transport equation (A 2. 1)) for the Riemann problem is (Bear, 1979)

$\frac{\mathrm{c}[\mathrm{x}, \mathrm{t}]}{\mathrm{c}_{0}}=\frac{1}{2}\left(\operatorname{erfc} \frac{\mathrm{x}-\frac{\mathrm{v}_{0} \mathrm{t}}{\mathrm{R}}}{2 \sqrt{\frac{\mathrm{Dt}}{\mathrm{R}}}}+\mathrm{e}^{2 \mathrm{v}_{0} / \mathrm{D}} \operatorname{erfc} \frac{\mathrm{x}+\frac{\mathrm{v}_{0} t}{\mathrm{R}}}{2 \nmid \sqrt{\frac{\mathrm{Dt}}{\mathrm{R}}}}\right)$

where

$\mathrm{v}_{0}=\frac{\mathrm{v}_{\mathrm{W}}}{\phi}$

12 A.2.4 Proofs of (A 2. 8) and (A 2. 10):

Integration of Transport Equation Assuming a Traveling Wave

Integration of the transport equation (A 2. 9) will be shown first. For the traveling wave solution (A 2. 6), (A 2.9) becomes an ordinary differential equation

$\frac{d}{d s}\left[-\sigma\left(\phi c+C^{*}\right)+v_{w} c-D c^{\prime}\right]=0$,

from which $c^{\prime}=\mathrm{dc} / \mathrm{ds}$ can be calculated.

$\mathrm{c}^{\prime}=\frac{1}{\mathrm{~V}_{\mathrm{w}}} \frac{\mathrm{d}}{\mathrm{ds}}\left[\sigma\left(\phi c+\mathrm{C}^{*}\right)+D \mathrm{c}^{\prime}\right]=0$.

Since $c_{+}^{\prime}=0$, the integral of (A 2.13) from $c_{+}$to $c$

$c-c_{+}=\frac{1}{V_{w}}\left\{\sigma\left[\phi\left(c-c_{+}\right)+C^{*}-C_{+}^{*}\right]+D\left(c^{\prime}-c^{\prime}\right)\right\}$

can be simplified and solved for $\mathrm{c}^{\prime}$ 


$$
\begin{aligned}
\mathrm{c}^{\prime} & =\frac{1}{\mathrm{D}}\left\{\left(\mathrm{c}-\mathrm{c}_{+}\right)\left(\mathrm{v}_{\mathrm{w}}-\sigma \phi\right)-\sigma\left(\mathrm{C}^{*}-\mathrm{C}_{+}^{*}\right)\right\}= \\
& =\frac{\mathrm{v}_{\mathrm{w}}-\sigma \phi}{\mathrm{D}}\left\{\left(\mathrm{c}-\mathrm{c}_{+}\right)-\frac{\sigma}{\mathrm{v}_{\mathrm{w}}-\sigma \phi}\left(\mathrm{C}^{*}-\mathrm{C}_{+}^{*}\right)\right\} .
\end{aligned}
$$

Replacing (see (A 2.7))

$$
\mathrm{v}_{\mathrm{w}}-\sigma \phi=\mathrm{v}_{\mathrm{w}}\left(1-\frac{1}{\mathrm{R}}\right) \text { and } \frac{\sigma}{\mathrm{v}_{\mathrm{w}}-\sigma \phi}=\frac{\Delta \mathrm{c}}{\Delta \mathrm{C}^{*}}
$$

(A 2. 15) appears as

$$
\begin{aligned}
c^{\prime} \quad & =\frac{v_{w}\left(1-\frac{1}{R}\right)}{D}\left\{\left(c-c_{+}\right)-\frac{\Delta c}{\Delta C^{*}}\left(C^{*}-C_{+}^{*}\right)\right\}= \\
& =\Delta c \frac{v_{w}\left(1-\frac{1}{R}\right)}{D}\left\{\frac{c-c_{+}}{\Delta c}-\frac{C^{*}-C_{+}^{*}}{\Delta C^{*}}\right\} .
\end{aligned}
$$

After introducing

$\widehat{\mathrm{c}}=\frac{\mathrm{c}-\mathrm{c}_{+}}{\Delta \mathrm{c}}, \widehat{\mathrm{C}}^{*}=\frac{\mathrm{C}^{*}-\mathrm{C}_{+}^{*}}{\Delta \mathrm{C}^{*}}$

(A 2.16) becomes

$$
\frac{\mathrm{dc}}{\mathrm{ds}}=\Delta \mathrm{c} \frac{\mathrm{V}_{\mathrm{w}}\left(1-\frac{1}{\mathrm{R}}\right)}{\mathrm{D}}\left\{\hat{\mathrm{c}}-\widehat{C}^{*}\right\}
$$

The reciprocal of $\mathrm{dc} / \mathrm{ds}$ is integrated from $\mathrm{c}_{+}$to $\mathrm{c}$

$$
\int_{c_{+}}^{c} \frac{d s}{d c} d c=s(c)-s\left(c_{+}\right)=\frac{D}{v_{w}\left(1-\frac{1}{R}\right)} \int_{c_{+}}^{c} \frac{d \hat{c}-\widehat{C^{*}}}{c} .
$$

For the case of non equilibrium transport with relaxation the asymptotic profile can be calculated similarly, since -after introducing the traveling wave solution into (A 2.4)- the resulting ordinary differential equation is similar to (A 2. 12): 
$\frac{d}{d s}\left[-\sigma\left(\phi c+C^{*}\right)+v_{w} c-2 \sigma^{2} \varepsilon C^{* \prime} c^{\prime}\right]=0$

Replacing in (A 2. 12) D with $2 \sigma^{2} \varepsilon C^{* \prime}$ gives the profile for relaxation. (Note that $\mathrm{C}^{* \prime}$ depends on $\mathrm{c}$ and has to placed under the integral.)

$$
\int_{c_{+}}^{c} \frac{d s}{d c} d c=s(c)-s\left(c_{+}\right)=\frac{2 \sigma^{2} \varepsilon}{v_{W}\left(1-\frac{1}{R}\right)} \int_{c_{+}}^{c} \frac{C^{* \prime} d \widehat{c}-\widehat{C}}{C^{*}}
$$

\section{A.2.5 Example: Langmuir Adsorption}

Silver adsorbs following a Langmuir type isotherm

$$
\mathrm{C}^{*}(\mathrm{c})=\mathrm{X}_{\mathrm{T}} \frac{\mathrm{kc}}{1+\mathrm{kc}}
$$

The Langmuir constant $\mathrm{k}$ is composed of the exchange constant a for $\mathrm{Ag} / \mathrm{H}$ exchange and the surface hydrolysis constant $\mathrm{k}_{2}$, both of which are defined as adsorption mass action constants. Referring to the adsorbing surface site on an oxide as $\mathrm{XO}$, the site occupied by silver is XOAg and the ones occupied by one or two protons are $\mathrm{XOH}$ and $\mathrm{XOH}_{2}$, respectively (Dzombak and Morel, 1990). The adsorption reactions can be described by the following mas action laws, where the symbols $\mathrm{XOAg}, \mathrm{XOH}_{2}, \mathrm{XOH}$ and $\mathrm{XO}$ are used for the corresponding adsorbed concentrations, e.g. $\mathrm{XOAg}=\mathrm{C}^{*}$

$$
\begin{aligned}
& \mathrm{XOAg}=\alpha \mathrm{XOH} \frac{\mathrm{M}}{\mathrm{H}}, \\
& \mathrm{XOH}_{2}=\mathrm{k}_{1} \mathrm{P} \mathrm{XOH} \mathrm{H}, \\
& \mathrm{XO}=\frac{\mathrm{k}_{2}}{\mathrm{P}} \frac{\mathrm{XOH}}{\mathrm{H}^{+}} .
\end{aligned}
$$

$\mathrm{P}$ is an electrostatic correction factor (Dzombak and Morel, 1990)

$$
\mathrm{P}=\exp \left(-\frac{\mathrm{F} \psi}{\mathrm{RT}}\right)
$$

where $\psi$ (unit: Volt $=$ Joule/Coulomb) is the electrostatic potential at the adsorbing surface, F (96485 Coulomb/mol) is the Faraday con- 
stant, R (8.31 Joule/(mol Kelvin)) is the gas constant and T (Kelvin) is the absolute temperature.

The electrostatic correction factor is generally a function of the composition of the aqueous solution. In dilute systems, i.e. at ionic strengths $\mathrm{I}=(1 / 2) \sum \mathrm{zi}^{2} \mathrm{c}_{\mathrm{i}} \leq 10^{\wedge}-4 \mathrm{M}$, where $\mathrm{z}_{\mathrm{i}}$ and $\mathrm{c}_{\mathrm{i}}$ are the charge and concentration of component $\mathrm{i}$ in solution, $\mathrm{P}$ can be approximated by

$\mathrm{P}=\frac{\sqrt{\frac{\mathrm{k}_{2}}{\mathrm{k}_{1}}}}{\mathrm{H}}$.

It follows from (A 2. 25) that

$\mathrm{XOH}_{2}=\mathrm{XO}=\sqrt{\mathrm{k}_{1} \mathrm{k}_{2}} \mathrm{XOH}$.

Using $X_{\mathrm{T}}$, the concentration of adsorption sites, and (15') in (A 2. 22) - (14")

$\mathrm{X}_{\mathrm{T}}=\mathrm{XOH}_{2}+\mathrm{XOH}+\mathrm{XO}+\mathrm{XOM}=\mathrm{XOH}\left(1+2 \sqrt{\mathrm{k}_{1} \mathrm{k}_{2}}+\alpha \frac{\mathrm{M}}{\mathrm{H}}\right)$,

we can construct the isotherm for silver,

$\mathrm{XOM}(\mathrm{M}, \mathrm{H})=\mathrm{X}_{\mathrm{T}} \frac{\alpha \mathrm{M}}{\alpha \mathrm{M}+\mathrm{H}\left(1+2 \sqrt{\mathrm{k}_{1} \mathrm{k}_{2}}\right)}$,

which can be brought into the form (A 2. 21) when the proton concentration is held constant by buffers:

$\operatorname{XOM}(M, H)=X_{T} \frac{\frac{\alpha}{H\left(1+2 \sqrt{k_{1} k_{2}}\right)} M}{1+\frac{\alpha}{H\left(1+2 \sqrt{\mathrm{k}_{1} \mathrm{k}_{2}}\right)} M}$.

Thus,

$\mathrm{k}=\frac{\alpha}{\mathrm{H}\left(1+2 \sqrt{\mathrm{k}_{1} \mathrm{k}_{2}}\right)}$.

We get a similar expression for $\mathrm{k}$ for regions in $\{\mathrm{M}, \mathrm{H}\}$ space in which $\mathrm{P}$ is constant, e.g. 
$\mathrm{P}=1$

and either $\mathrm{XOH}_{2}$ or $\mathrm{XOH}_{2}+\mathrm{XOH}$ being negligible. In the first case, i.e. when

$\mathrm{XOH}_{2}<<\mathrm{XOH}$.

the isotherm is

$\mathrm{XOM}(\mathrm{M}, \mathrm{H})=\mathrm{X}_{\mathrm{T}} \frac{\alpha \mathrm{M}}{\alpha \mathrm{M}+\mathrm{H}+\mathrm{k}_{2}}=\frac{\frac{\alpha}{\mathrm{H}+\mathrm{k}_{2}} \mathrm{M}}{\frac{\alpha}{\mathrm{H}+\mathrm{k}_{2}} \mathrm{M}+1}$,

and, thus,

$\mathrm{k}=\frac{\alpha}{\mathrm{H}+\mathrm{k}_{2}}$

In the second case, i.e. at $\mathrm{H} \ll \mathrm{k}_{2}$, the isotherm is

$\operatorname{XOM}(M, H)=X_{T} \frac{\alpha M}{\alpha M+k_{2}}=\frac{\frac{\alpha}{k_{2}} M}{\frac{\alpha}{k_{2}} M+1}$,

and the Langmuir factor is

$\mathrm{k}=\frac{\alpha}{\mathrm{k}_{2}}$

At $\mathrm{H}=\mathrm{k}_{2}$ all expressions for $\mathrm{k}$, (A 2. 30), (A 2. 32) and (A 2. 34), are similar. For this example, expression (A 2. 34) is chosen.

With the data from Dzombak and Morel (1990)

$\alpha=10^{-1.72}$

$\mathrm{k}_{2}=10^{-8.9}$ mole/liter

we get

$\mathrm{k}=\alpha / \mathrm{k}_{2}=1.810^{7}$ liter $/$ mole.

(A 2. 37)

The profiles in figure 1 were calculated based on the following data (A 2. 38): 
$\mathrm{X}_{\mathrm{T}}=510^{-3} \mathrm{HFO}$, concentration of sites adsorbing Ag, (Dzombak and Morel, 1990).

$\mathrm{HFO}=10^{-3}$ mol hydrous ferric oxides $\left(\mathrm{Fe}_{2} \mathrm{O}_{3}\right)$ per liter of soil $=0.09 \mathrm{~g}$ hydrous ferric oxides per liter of soil.

c_ $\quad=5.010^{-4} \mathrm{mg} \mathrm{Ag}$ per liter of feed water.

$\mathrm{c}_{+} \quad=0$, Ag concentration in undisturbed soil column.

8. 10

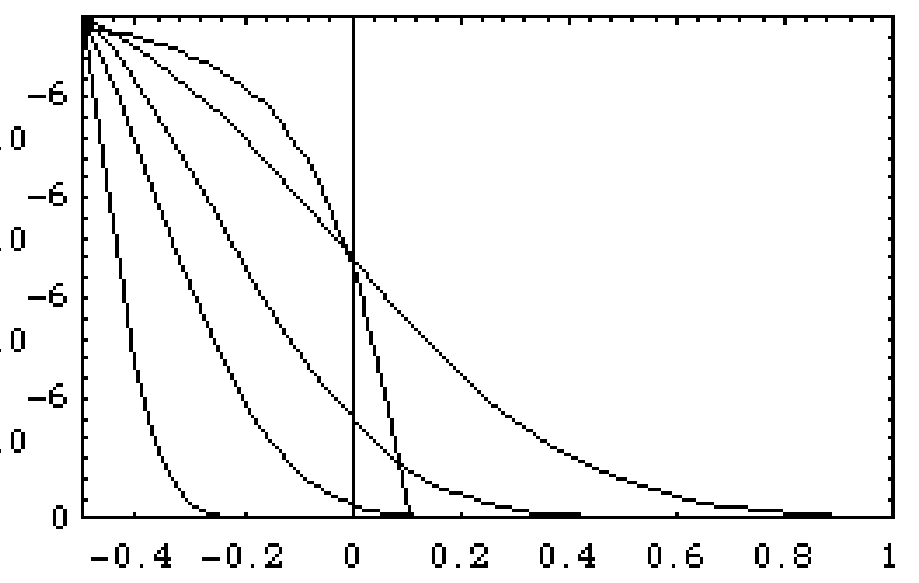

Fig. 1: Profiles for linear and non-linear adsorption, calculated for the same retardation $(\mathrm{R}=2.7$, according to (A 2.7)). Traveling wave -the curve without tail- was calculated using (A 2. 10). Profiles for linear adsorption isotherm calculated for times $t=0.1$, 0.5, 1, 2 yr, using (A 2. 11). Element and environment: silver in hydrous ferric oxide coated inert sediment matrix. Abscissa: distance (units: m), ordinate: concentration (mol/Liter). Adsorption data from Dzombak and Morel (1990).

$\phi \quad=0.3$, fraction of soil filled with liquid phase (water).

$\mathrm{v}_{0} \quad=\mathrm{v}_{\mathrm{W}} / \phi=0.5 \mathrm{~m} / \mathrm{yr}$, speed of liquid phase (water).

The traveling wave was calculated by integrating (A 2. 10) and plotting c vs. $s$. The profiles $\mathrm{c}(\mathrm{x}, \mathrm{t})$ for the linear isotherm were calculated at $\mathrm{t}=0.1,0.5,1$ and 2 years, using (A 2. 11).

\section{A.3 Langmuir and Exchange Type Isotherms:} Shocks and Rarefaction Waves are Lines and Coincide 
The first part of this proof concerns rarefaction waves, i.e. solutions of the set of differential equations (7). Using $c_{j}$ and $C^{*} j$ to denote soluble and adsorbed concentrations as functions of $\xi$, this equation reads

$\left(\frac{\mathrm{V}_{\mathrm{w}}}{\phi}-\xi\right) \frac{d \mathrm{C}_{\mathrm{j}}}{\mathrm{d} \xi}-\frac{\xi}{\phi} \frac{\mathrm{dC} \mathrm{C}_{\mathrm{j}}^{*}}{\mathrm{~d}^{\xi} \xi}=0 \quad\left(\mathrm{j}=1,2, \ldots, \mathrm{N}_{0}\right)$.

Dividing by $\mathrm{dc}_{\mathrm{j}} / \mathrm{d} \xi$ we get

$$
\left(\frac{V_{w}}{\phi}-\xi\right)-\frac{\xi}{\phi} \frac{d C_{j}^{*}}{d c_{j}}=0 \quad\left(j=1,2, \ldots, N_{0}\right) .
$$

Because $\mathrm{v}_{\mathrm{w}} / \phi-\xi$ is the same for all $\mathrm{j}$, this equation can be written as

$$
\frac{\mathrm{dC}_{1}^{*}}{\mathrm{dc}_{1}}=\frac{\mathrm{dC}_{2}^{*}}{\mathrm{dc}_{2}}=\ldots, \frac{\mathrm{dC}_{\mathrm{N}_{0}}^{*}}{\mathrm{dc}_{\mathrm{N}_{0}}},
$$

which is called differential coherence condition (Helfferich and Klein, 1970).

Because the change $\mathbf{c}_{\mathrm{k}}-\mathbf{c}_{\mathrm{k}-1}$ of the $\mathrm{N}_{0}$ components of the concentration vector across a $\mathrm{k}$-wave is restricted by $\mathrm{N}_{0}-1$ conditions (A 3 . 2 ), the concentration vector $\mathbf{c}_{\mathrm{k}}$ can be expressed as functions of one parameter if $\mathbf{c}_{\mathrm{k}-1}$ is given. Here we choose $\delta$ which is a measure of the sum of all adsorbed concentrations, the surface coverage

$$
\frac{1}{\mathrm{X}_{\mathrm{T}}} \sum_{\mathrm{j}=1}^{\mathrm{N}_{0}} \mathrm{C}_{\mathrm{j}}^{*}=1-\frac{1}{\delta}=\text { surface coverage }
$$

Correspondingly, the Langmuir isotherm reads now

$\mathrm{C}_{\mathrm{k}}^{*}(\delta)=\mathrm{X}_{\mathrm{T}} \frac{\mathrm{k}_{\mathrm{k}} \mathrm{c}_{\mathrm{k}}(\delta)}{\delta}$,

It is this structure of the isotherm that causes the waves to be linear, as will be shown now (A 3.5 - A 3.13).

The $\mathrm{N}_{0}$ derivatives $\mathrm{dC}^{*} \cdot \mathrm{d} \mathrm{d}_{\mathrm{j}}$ in the direction across the $\mathrm{k}$-wave in composition space are 
$\frac{d C_{j}^{*}}{d c_{j}}=\frac{C_{j}^{*}}{c_{j}^{\prime}}=\frac{X_{T} k_{j}}{\delta^{2}}\left(\delta-\frac{c_{j}}{c_{j}^{\prime}}\right)$.

where the prime denotes the derivative with respect to $\delta$. Using (A 3. 5) in (A 3. 2) gives us

$$
\mathrm{k}_{1}\left(\delta-\frac{\mathrm{c}_{1}}{\mathrm{c}_{1}{ }^{\prime}}\right)=\mathrm{k}_{2}\left(\delta-\frac{\mathrm{c}_{2}}{\mathrm{c}_{2}^{\prime}}\right)=\ldots=\mathrm{k}_{\mathrm{N}_{0}}\left(\delta-\frac{\mathrm{c}_{\mathrm{N}_{0}}}{\mathrm{c}_{\mathrm{N}_{0}{ }^{\prime}}}\right. \text {. }
$$

Differentiating each term in the equality again with respect to $\delta$ gives for the $\mathrm{j}$-term

$$
\frac{\mathrm{d}}{\mathrm{d} \delta} \mathrm{k}_{\mathrm{j}}\left(\delta-\frac{\mathrm{c}_{\mathrm{j}}}{\mathrm{c}_{\mathrm{j}}{ }^{\prime}}\right)=\mathrm{k}_{\mathrm{j}}\left(1-1+\mathrm{c}_{\mathrm{j}} \frac{\mathrm{c}_{\mathrm{j}}{ }^{\prime \prime}}{\mathrm{c}_{\mathrm{j}}{ }^{2}}\right)=\frac{\mathrm{k}_{\mathrm{j}} \mathrm{c}_{\mathrm{j}}{ }^{\prime \prime}}{\frac{1}{\mathrm{c}_{\mathrm{j}}} \mathrm{c}_{\mathrm{j}}{ }^{2}}
$$

With that in mind (A 3.6) can be rearranged

$\frac{\mathrm{k}_{1} \mathrm{c}_{1}{ }^{\prime \prime}}{\frac{1}{\mathrm{c}_{1}} \mathrm{c}_{1}{ }^{\prime 2}}=\frac{\mathrm{k}_{2} \mathrm{c}_{2}{ }^{\prime \prime}}{\frac{1}{\mathrm{c}_{2}} \mathrm{c}_{2}{ }^{\prime 2}}=\ldots=\frac{\mathrm{k}_{\mathrm{N}_{0}} \mathrm{c}_{\mathrm{N}_{0}}{ }^{\prime \prime}}{\frac{1}{\mathrm{c}_{\mathrm{N}_{0}}} \mathrm{c}_{\mathrm{N}_{0}}{ }^{2}}$.

In equalities like $a_{1} / b_{1}=a_{2} / b_{2}=a_{3} / b_{3}$ the following equation holds: $a_{j} b_{i}=\Sigma a_{k} / \sum b_{k}$, where the sum extends over $k=1$ to 3 and $i$ is 1,2 or 3. This is applied to (A 3.7):

$\frac{\mathrm{k}_{1} \mathrm{c}_{1}{ }^{\prime \prime}}{\frac{1}{\mathrm{c}_{1}} \mathrm{c}_{1}{ }^{\prime 2}}=\frac{\mathrm{k}_{2} \mathrm{c}_{2}{ }^{\prime \prime}}{\frac{1}{\mathrm{c}_{2}} \mathrm{c}_{2}^{\prime 2}}=\ldots=\frac{\mathrm{k}_{\mathrm{N}_{0}} \mathrm{c}_{\mathrm{N}_{0}}{ }^{\prime \prime}}{\frac{1}{\mathrm{c}_{\mathrm{N}_{0}}} \mathrm{c}_{\mathrm{N}_{0}}{ }^{\prime 2}}=\frac{\sum_{\mathrm{j}=1}^{\mathrm{N}_{0}} \mathrm{k}_{\mathrm{j}} \mathrm{c}_{\mathrm{j}}{ }^{\prime \prime}}{\sum_{\mathrm{j}=1}^{\mathrm{N}_{0}} \frac{1}{\mathrm{c}_{\mathrm{j}}} \mathrm{c}_{\mathrm{j}}{ }^{\prime 2}}$.

From the definition of $\delta$ we know that

$$
\sum_{\mathrm{j}=1}^{\mathrm{N}_{0}} \mathrm{k}_{\mathrm{j}} \mathrm{c}_{\mathrm{j}}{ }^{\prime}=0
$$

Therefore, any solution of (A 3.8) must meet the following condition

$$
\mathrm{c}_{\mathrm{j}}{ }^{\prime \prime}=0
$$


or

$\sum_{j=1}^{N_{0}} \frac{c_{j}^{\prime 2}}{c_{j}}=0$

Integration of (A 3. 10) tells us that in each k-wave all components $c_{j}$ of the concentration vector $\mathbf{c}$ are linear functions of the common parameter $\delta$ :

$c_{j} "=0$

i.e.

$c_{\mathrm{j}}^{\prime}=\mathrm{a}_{\mathrm{j}}$, or $\mathbf{c}^{\prime}=\mathbf{a}$

with $\mathbf{a}=\left\{\mathrm{a}_{1}, \mathrm{a}_{2}, \ldots, \mathrm{aNo}\right\}$. Because -for any wave, e.g. the k-wave- the $\mathrm{a}_{\mathrm{j}}$ are integration constants, $\mathbf{a}$ is independent of $\mathbf{c}$, i.e. independent from the location on the k-wave. Consequently the k-wave is a (straight) line in composition space.

Comparing (A 3. 12) with (33) one can see that $\mathbf{a}$ is the right eigenvector $\mathbf{r}_{\mathrm{k}}$ corresponding to the $\mathrm{k}$-wave. Thus, the vector describing the change of $\mathbf{c}$ across the k-wave

$\mathbf{c}^{\prime}=\mathbf{r}_{\mathrm{k}}$

is independent of $\mathbf{c}$.

Integration of (A 3. 12) will give us the k-wave. With $\delta_{\mathrm{k}-1}-\delta_{\mathrm{k}}$ denoting the change of the parameter $\delta$ across the k-wave and with the nomenclature introduced in figure 1 , we get the following expression for the solution of the Riemann problem

$\mathbf{c}_{\mathrm{k}}=\mathbf{c}_{\mathrm{k}-1}+\mathbf{r}_{\mathrm{k}}\left(\delta_{\mathrm{k}-1}-\delta_{\mathrm{k}}\right), \quad$ with $\mathbf{r}_{\mathrm{k}}$ being independent of $\mathbf{c}$.

(A 3. 11) gives another condition for the slopes $c_{j}^{\prime}$ when $c_{j} "=0$. In a 2-component-system (A 3. 11) gives the equation of a curve $c_{2}\left(c_{1}\right)$ having as tangents the lines which meet (A 3.13) (see appendix 12A 4).

It will now be shown that k-shocks coincide with k-rarefaction waves (A 3. 13). The concentration changes across a k-shock by a finite amount rather than by differential amounts as across a rarefaction wave. Accordingly, the mass conservation law involves differ- 
ences rather than differentials. Otherwise the conservation laws are the same as for rarefaction waves (i.e. (3))

$$
\frac{\Delta}{\Delta \mathrm{t}}\left\{\phi \mathrm{c}_{\mathrm{i}}(\mathrm{x}, \mathrm{t})+\mathrm{C}_{\mathrm{i}}^{*}\left(\mathrm{c}_{1}, \mathrm{c}_{2}, \ldots, \mathrm{c}_{\mathrm{N}_{0}}\right)\right\}+\mathrm{v}_{\mathrm{w}} \frac{\Delta}{\Delta \mathrm{x}} \mathrm{c}_{\mathrm{i}}(\mathrm{x}, \mathrm{t})=0 \quad\left(\mathrm{i}=1,2, \ldots, \mathrm{N}_{0}\right) \text { (A 3. 14) }
$$

or after dividing by $\phi$ and multiplying with $\Delta \mathrm{x}$

$\Delta\left(\mathrm{c}_{\mathrm{i}}+\frac{1}{\phi} \mathrm{C}_{\mathrm{i}}^{*}\right) \frac{\Delta \mathrm{x}}{\Delta \mathrm{t}}-\frac{\mathrm{V}_{\mathrm{w}}}{\phi} \Delta \mathrm{c}_{\mathrm{i}}=0$

Solving for $\Delta \mathrm{x} / \Delta \mathrm{t}=\sigma_{\mathrm{k}}$, the speed of the k-shock,

$\sigma_{\mathrm{k}}=\frac{\mathrm{v}_{\mathrm{w}}}{\phi} \frac{\Delta \mathrm{c}_{\mathrm{i}}}{\Delta\left(\mathrm{c}_{\mathrm{i}}+\frac{1}{\phi} \mathrm{C}_{\mathrm{i}}^{*}\right)}=\frac{\frac{\mathrm{v}_{\mathrm{w}}}{\phi}}{1+\frac{1}{\phi} \frac{\Delta \mathrm{C}_{\mathrm{i}}^{*}}{\Delta \mathrm{c}_{\mathrm{i}}}}, \quad\left(\mathrm{i}=1,2, \ldots, \mathrm{N}_{0}\right)$

(A 3. 15) is the so-called "Rankine-Hugoniot relation". It has $\mathrm{N}_{0}$ physical solutions (Lax, 1973).

The speed of the k-shock is by a factor $\mathrm{R}_{\mathrm{k}}$ smaller than the speed of the water. $R_{k}$ is called "retardation of the k-shock".

$\mathrm{R}_{\mathrm{k}}=1+\frac{1}{\phi} \frac{\Delta_{\mathrm{k}} \mathrm{C}_{\mathrm{i}}^{*}}{\Delta_{\mathrm{k}} \mathrm{C}_{\mathrm{i}}}$

The Rankine-Hugoniot relation (integral coherence condition) can be written in a form analogous to (A 3. 2):

$\frac{\Delta \mathrm{C}_{1}^{*}}{\Delta \mathrm{c}_{1}}=\frac{\Delta \mathrm{C}_{2}^{*}}{\Delta \mathrm{c}_{2}}=\ldots,=\frac{\Delta \mathrm{C}_{\mathrm{N}_{0}}^{*}}{\Delta \mathrm{c}_{\mathrm{N}_{0}}} \quad$ for each $\mathrm{k}$-shock $\left(\mathrm{k}=1,2, \ldots, \mathrm{N}_{0}\right)$

As was shown in (A 3.5 - 13), the relationship (A 3. 2) is satisfied when the concentrations $c_{j}$ are linear functions of a parameter $\delta$. Writing $c_{j}(\delta)$ as

$c_{j}=a_{j} \delta+b_{j}$,

we get for the differential coherence condition 
$\frac{d C_{j}^{*}}{d c_{j}}=\frac{\frac{d C_{j}^{*}}{d \delta}}{\frac{d c_{j}}{d \delta}}=-X_{T} k_{j} \frac{b_{j}}{a_{j} \delta^{2}}$

and for the integral coherence condition

$\frac{\Delta C_{j}^{*}}{\Delta c_{j}}=-X_{T} k_{j} \frac{b_{j}}{a_{j} \delta(\delta+\Delta)}$,

where $\delta$ and $\delta+\Delta$ are the values of the parameter left and right of the discontinuity.

Replacing $\Delta C^{*} j / \Delta c_{j}$ in the integral coherence condition with the value given in (A 3.20) results in

$-\mathrm{X}_{\mathrm{T}} \mathrm{k}_{1} \frac{\mathrm{b}_{1}}{\mathrm{a}_{1} \delta(\delta+\Delta)}=-\mathrm{X}_{\mathrm{T}} \mathrm{k}_{2} \frac{\mathrm{b}_{2}}{\mathrm{a}_{2} \delta(\delta+\Delta)}=\ldots=-\mathrm{X}_{\mathrm{T}_{\mathrm{N}} \mathrm{N}_{0}} \frac{\mathrm{b}_{\mathrm{N}_{0}}}{\mathrm{a}_{\mathrm{N}_{0}} \delta(\delta+\Delta)}$

The differential coherence condition with $\mathrm{dC}^{*} \mathrm{j} / \mathrm{dc}_{\mathrm{j}}$ replaced with (A 3 . 19) is

$-\mathrm{X}_{\mathrm{T}} \mathrm{k}_{1} \frac{\mathrm{b}_{1}}{\mathrm{a}_{1} \delta^{2}}=-\mathrm{X}_{\mathrm{T}} \mathrm{k}_{2} \frac{\mathrm{b}_{2}}{\mathrm{a}_{2} \delta^{2}}=\ldots=-\mathrm{X}_{\mathrm{T}} \mathrm{k}_{\mathrm{N}_{0}} \frac{\mathrm{b}_{\mathrm{N}_{0}}}{\mathrm{a}_{\mathrm{N}_{0}} \delta^{2}}$.

After having canceled common factors in (A 3. 21) and in (A 3. 22) we get the same condition for the $\mathrm{a}_{\mathrm{i}}, \mathrm{b}_{\mathrm{i}}$ and $\mathrm{k}_{\mathrm{i}}$ :

$\mathrm{k}_{1} \frac{\mathrm{b}_{1}}{\mathrm{a}_{1}}=\mathrm{k}_{2} \frac{\mathrm{b}_{2}}{\mathrm{a}_{2}}=\ldots=\mathrm{k}_{\mathrm{N}_{0}} \frac{\mathrm{b}_{\mathrm{N}_{0}}}{\mathrm{a}_{\mathrm{N}_{0}}}$.

Thus the same line (A 3. 18) satisfies the differential as well as the integral coherence condition. In other words: k-shocks coincide with k-rarefaction waves.

\section{A.4 Waves in a Two-Component System with Langmuir Isotherm}

Using $\mathrm{c}_{\mathrm{j}}$ and $\mathrm{C}^{*} \mathrm{j}$ to denote soluble and adsorbed concentrations as functions of $\xi$, the equilibrium transport equation (3) reads 
$\left(\frac{V_{w}}{\phi}-\xi\right) \frac{d c_{j}}{d \xi}-\frac{\xi}{\phi} \frac{d C_{j}^{*}}{d \xi}=0 \quad(j=1,2)$.

The corresponding differential coherence condition (9d) is

$\frac{\mathrm{dC}_{2}^{*}}{\mathrm{dc}_{2}}-\frac{\mathrm{dC}_{1}^{*}}{\mathrm{dc}_{1}}=0$

Writing the directional derivatives in (A 4. 2) in terms of partial derivatives in composition space

$\frac{d C_{j}^{*}}{d c_{j}}=\frac{\partial C_{j}^{*}}{\partial c_{1}}+\frac{\partial C_{j}^{*}}{\partial c_{2}} \frac{d c_{2}}{d c_{1}}$

and multiplying with the derivative $\mathrm{dc}_{1} / \mathrm{dc}_{2}$ gives us an expression equivalent to $(10 \mathrm{c})$

$\frac{\partial \mathrm{C}_{2}^{*}}{\partial \mathrm{c}_{1}}\left(\frac{\mathrm{dc}_{1}}{\mathrm{dc}_{2}}\right)^{2}-\left(\frac{\partial \mathrm{C}_{1}^{*}}{\partial \mathrm{c}_{1}}-\frac{\partial \mathrm{C}_{2}^{*}}{\partial \mathrm{c}_{2}}\right) \frac{\mathrm{dc}_{1}}{\mathrm{dc}_{2}}-\frac{\partial \mathrm{C}_{1}^{*}}{\partial \mathrm{c}_{2}}=0$

At this point the specific form of the isotherm is introduced:

$\mathrm{C}_{\mathrm{j}}^{*}=\frac{\Gamma_{\mathrm{j}} \mathrm{c}_{\mathrm{j}}}{1+\mathrm{B}_{1} \mathrm{c}_{1}+\mathrm{B}_{2} \mathrm{C}_{2}}=\frac{\Gamma_{\mathrm{j}} \mathrm{c}_{\mathrm{j}}}{\delta}$

i.e. for the 2-component Langmuir isotherm

$\Gamma_{\mathrm{j}}=\mathrm{X}_{\mathrm{T}} \mathrm{k}_{\mathrm{j}}, \mathrm{B}_{\mathrm{j}}=\mathrm{k}_{\mathrm{j}}$

For ion exchange in a 3 -species system with constant total concentration $\mathrm{c}=\mathrm{c}_{1}+\mathrm{c}_{2}+\mathrm{c}_{3}$

$$
C_{j}^{*}(\mathbf{c})=X_{T} \frac{\frac{\alpha_{j 3}}{c} c_{j}}{\frac{\alpha_{13}-1}{c} c_{1}+\frac{\alpha_{23}-1}{c} c_{2}+1}
$$

we have

$\Gamma_{\mathrm{j}}=\mathrm{X}_{\mathrm{T}} \frac{\alpha_{\mathrm{j} 3}}{\mathrm{c}}, \mathrm{B}_{\mathrm{j}}=\frac{\alpha_{\mathrm{j} 3}-1}{\mathrm{c}}$. 
The partial derivative of the isotherm is then

$\frac{\partial C_{\mathrm{i}}^{*}}{\partial c_{\mathrm{j}}}=\frac{\Gamma_{\mathrm{i}}}{\delta}\left(\frac{\mathrm{B}_{\mathrm{j}} \mathrm{c}_{\mathrm{i}}}{-\delta}+\delta_{\mathrm{ij}}\right)$

where the Kronecker symbol $\delta_{\mathrm{ij}}=0$ for $\mathrm{i} \neq \mathrm{j}$ and $\delta_{\mathrm{ii}}=1$.

With (A 4. 7) the equation (A 4. 3) assumes the following form

$\Gamma_{2} \mathrm{~B}_{1} \mathrm{c}_{2}\left(\frac{\mathrm{dc_{1 }}}{\mathrm{dc}_{2}}\right)^{2}+\left(\Gamma_{1} \mathrm{~B}_{2} \mathrm{c}_{2}+\Gamma_{1}-\Gamma_{2} \mathrm{~B}_{1} \mathrm{c}_{1}-\Gamma_{2}\right) \frac{\mathrm{dc}_{1}}{\mathrm{dc}_{2}}-\Gamma_{1} \mathrm{~B}_{2} \mathrm{c}_{1}=0$.

Dividing through by $\mathrm{G}_{2} \mathrm{~B}_{1}$ (note that $\mathrm{G}_{2} \mathrm{~B}_{1}=\mathrm{G}_{1} \mathrm{~B}_{2}$ ) and abbreviating

$\mathrm{k}=\frac{1}{\mathrm{~B}_{1}}\left(1-\frac{\Gamma_{1}}{\Gamma_{2}}\right) ; \overline{\mathrm{c}}_{\mathrm{j}}=\frac{\mathrm{c}_{\mathrm{j}}}{\mathrm{k}}$

the differential equation (A 4. 8) for $\mathrm{c}_{1}\left(\mathrm{c}_{2}\right)$ can be written as

$\bar{c}_{2}\left(\frac{d \bar{c}_{1}}{d \bar{c}_{2}}\right)^{2}-\left(1+\bar{c}_{1}-\bar{c}_{2}\right) \frac{d \bar{c}_{1}}{d \bar{c}_{2}}-\bar{c}_{1}=0$

Glueckauf (1949) solved this equation by differentiating once more with respect to $\mathrm{c}_{2}$

$\frac{\mathrm{d}^{2} \overline{\mathrm{c}}_{1}}{\mathrm{dc}_{2}^{2}}\left\{2 \overline{\mathrm{c}}_{2} \frac{\mathrm{d \textrm {c } _ { 1 }}}{\mathrm{dc_{2 }}}-\left(1+\overline{\mathrm{c}}_{1}-\overline{\mathrm{c}}_{2}\right)\right\}=0$

This equation is satisfied by a set of lines

$\frac{\mathrm{d}^{2} \mathrm{c}_{2}}{\mathrm{dc}_{1}^{2}}=0$

i.e.

$\mathrm{c}_{2}\left(\mathrm{c}_{1}\right)=\mathrm{a} \mathrm{c} \mathrm{c}_{1}+\mathrm{b}$

that are tangential to the solution of the equation

$2 \overline{\mathrm{c}}_{2} \frac{\mathrm{d} \mathrm{c}_{1}}{\mathrm{dc}_{2}}=1+\overline{\mathrm{c}}_{1}-\overline{\mathrm{c}}_{2}$ 
Using (A 4. 13) in (A 4. 10) gives

$\left(1+\overline{\mathrm{c}}_{1}-\overline{\mathrm{c}}_{2}\right)^{2}+4 \overline{\mathrm{c}}_{1} \overline{\mathrm{c}}_{2}=0$

which can be solved for $\mathrm{c}_{2}$

$\overline{\mathrm{c}}_{2}=1-\overline{\mathrm{c}}_{1} \pm 2 \sqrt{-\overline{\mathrm{c}}_{1}}$

(A 4. 14) is a parabola that touches the axes at $\bar{c}_{2}=1$ and $\bar{c}_{1}=-1$.

\section{A.5 Solution of the Riemann Problem with Riemann Invari- ants}

The solution of the Riemann problem makes use of the fact that the waves are (straight) lines in composition space, or -in other words- that the k-wave connecting constant states $\mathbf{c}_{\mathrm{k}-1}$ and $\mathbf{c}_{\mathrm{k}}$ adjacent to it is a line parallel to the right eigenvector $\mathbf{r}_{\mathrm{k}}$ of the Jacobi matrix of the isotherms, $\underline{\mathrm{Kd}}$ (see (33) and (A 3. 12), (A 3. 13)). With denoting proportionality

$\mathbf{c}_{\mathrm{k}}-\mathbf{c}_{\mathrm{k}-1} \sim \mathbf{r}_{\mathrm{k}}$

with

$\underline{\operatorname{Kd}}(\mathbf{c}) \mathbf{r}_{\mathrm{k}}(\mathbf{c})=\mathrm{kd}_{\mathrm{k}}(\mathbf{c}) \mathbf{r}_{\mathrm{k}}(\mathbf{c})$

and

$\mathbf{r}_{\mathrm{k}}(\mathbf{c})$ being constant across the k-wave.

The Jacobian $\underline{\mathrm{Kd}}(\mathbf{c})$ has been defined in (33).

In addition to (A 5. 1) - (A 5. 3) the solution uses only the biorthogonality of the left and right eigenvectors

$\mathbf{r}_{\mathrm{k}}(\mathbf{c}) \mathbf{l}_{\mathrm{j}}(\mathbf{c})=0, \quad(\mathrm{j} \neq \mathrm{k})$, where

$\mathbf{I}_{\mathrm{k}}(\mathbf{c}) \underline{\mathrm{Kd}}(\mathbf{c})=\mathrm{kd}_{\mathrm{k}}(\mathbf{c}) \mathbf{I}_{\mathrm{k}}(\mathbf{c})$.

We will need the following theorem in this appendix:

\section{Theorem:}


The left eigenvector corresponding to the eigenvalue $\operatorname{kd}_{j}\left(\mathbf{c}_{\mathrm{k}}\right)$ can be calculated from the Jacobians $\underline{\mathrm{Kd}}\left(\mathbf{c}_{-}\right)$and $\underline{\mathrm{Kd}}\left(\mathbf{c}_{+}\right)$as follows

$\mathbf{l}_{j}\left(\mathbf{c}_{k}\right)= \begin{cases}\mathbf{l}_{j}^{+}, & (j \leq k) \\ \mathbf{l}_{j}^{-}, & (j>k) .\end{cases}$

with $\mathbf{l}_{\mathbf{j}^{-}}=\mathbf{l}_{\mathbf{j}}\left(\mathbf{c}_{-}\right)$and $\mathbf{l}_{\mathbf{j}}{ }^{+}=\mathbf{l}_{\mathbf{j}}\left(\mathbf{c}_{+}\right)$.

\section{Proof:}

Because $\mathbf{r}_{\mathrm{k}}$ is constant across the k-wave,

$\mathbf{r}_{\mathrm{k}}\left(\mathbf{c}_{\mathrm{k}-1}\right)=\mathbf{r}_{\mathrm{k}}\left(\mathbf{c}_{\mathrm{k}}\right)$

so are (or can be chosen) the left eigenvectors that are orthogonal to $\mathbf{r}_{\mathrm{k}}$

$\mathbf{l}_{\mathrm{j}}\left(\mathbf{c}_{\mathrm{k}-1}\right)=\mathbf{l}_{\mathrm{j}}\left(\mathbf{c}_{\mathrm{k}}\right), \quad(\mathrm{j} \neq \mathrm{k})$.

Then the left eigenvectors in the fan of constant states $\mathbf{c}_{-}, \mathbf{c}_{1}, \mathbf{c}_{2}, \ldots, \mathbf{c}_{+}$ (see figure 1) are:

$\mathbf{l}_{1}\left(\mathbf{c}_{-}\right)=\mathbf{l}_{1}, \mathbf{l}_{2}(\mathbf{c}-)=\mathbf{l}_{2}, \ldots, \mathbf{l}_{\mathrm{N}_{0}}(\mathbf{c}-)=\mathbf{l}_{\mathrm{N}_{0}}$

$\mathbf{l}_{1}\left(\mathbf{c}_{1}\right)=\mathbf{l}_{1}^{+}, \mathbf{l}_{2}\left(\mathbf{c}_{1}\right)=\mathbf{l}_{2}^{-}, \ldots, \mathbf{l}_{\mathrm{N}_{0}}\left(\mathbf{c}_{1}\right)=\mathbf{l}_{\mathrm{N}_{0}}^{-}$

$\mathbf{l}_{1}\left(\mathbf{c}_{2}\right)=\mathbf{l}_{1}^{+}, \mathbf{l}_{2}\left(\mathbf{c}_{2}\right)=\mathbf{l}_{2}^{+}, \mathbf{l}_{3}\left(\mathbf{c}_{2}\right)=\mathbf{l}_{3}^{-}, \ldots, \mathbf{l}_{\mathrm{N}_{0}}\left(\mathbf{c}_{2}\right)=\mathbf{l}_{\mathrm{N}_{0}}$

$\mathbf{l}_{1}\left(\mathbf{c}_{+}\right)=\mathbf{l}_{1}^{+}, \ldots, \mathbf{l}_{\mathrm{N}_{0}-1}\left(\mathbf{c}_{+}\right)=\mathbf{l}_{\mathrm{N}_{0}-1}^{+}, \mathbf{l}_{\mathrm{N}_{0}}\left(\mathbf{c}_{+}\right)=\mathbf{l}_{\mathrm{N}_{0}}^{+}$

This can be written in the compact form (A 5. 6), q.e.d.

Let $\underline{L}\left(\mathbf{c}_{\mathrm{k}}\right)$ be the matrix the rows of which are the left eigenvectors corresponding to the eigenvalues of the Jacobian $\underline{\mathrm{Kd}}\left(\mathbf{c}_{\mathrm{k}}\right), \mathrm{kd}\left(\mathbf{c}_{\mathrm{k}}\right), \ldots$, $\mathrm{kd}_{\mathrm{No}}\left(\mathbf{c}_{\mathrm{k}}\right)$

$\underline{\mathrm{L}}\left(\mathbf{c}_{\mathrm{k}}\right)=\left[\begin{array}{c}\mathbf{l}_{1}\left(\mathbf{c}_{\mathrm{k}}\right) \\ \ldots . \\ \cdots \\ \mathbf{l}_{\mathrm{N}_{0}}\left(\mathbf{c}_{\mathrm{k}}\right)\end{array}\right]$. 
The $\mathrm{j}$-th row in this matrix is either $\mathbf{l}_{\mathrm{j}}{ }^{+}$or $\mathbf{l}_{\mathrm{j}}{ }^{-}$depending on $\mathbf{c}_{\mathrm{k}}$ (see (A 5. 9)). So, $\underline{\mathrm{L}}\left(\mathbf{c}_{\mathrm{k}}\right)$ is a known matrix.

The k-Riemann invariant is defined as the scalar function of the concentration vector that changes only across the k-wave and remains unchanged across all other waves.

Definition: Let $\nabla_{c}$ denote the gradient in concentration space, then the scalar function $\mathrm{wj}_{\mathrm{j}}(\mathbf{c})$ is the $\mathrm{j}$-Riemann invariant if

$\mathbf{r}_{\mathrm{k}} \nabla_{\mathrm{c}} \mathrm{w}_{\mathrm{j}}=0 \quad\left(\mathrm{j}=1,2, \ldots, \mathrm{k}-1, \mathrm{k}+1, \ldots, \mathrm{N}_{0}\right)$.

Thus, both the left eigenvector $\mathbf{l}_{\mathrm{k}}$ and the k-Riemann invariant have the property that they change only across the k-wave. So, for the Riemann invariants there exists a relationship similar to (A 5.6)

$w_{j}\left(c_{k}\right)= \begin{cases}w_{j}^{+}, & (j \leq k) \\ w_{j}^{-}, & (j>k)\end{cases}$

with $w_{j}+=w j(\mathbf{c}+)$ and $w j-=w j(\mathbf{c}-)$. The j-th component of the vector

$\mathbf{w}\left(\mathbf{c}_{\mathrm{k}}\right)=\left[\begin{array}{c}\mathrm{w}_{1}\left(\mathbf{c}_{\mathrm{k}}\right) \\ \ldots \\ \cdots \\ \mathrm{w}_{\mathrm{N}_{0}}\left(\mathbf{c}_{\mathrm{k}}\right)\end{array}\right]$

is thus either $w_{j}{ }^{+}$or $w_{j^{-}}$, depending on at what $\mathbf{c}_{\mathrm{k}}$ it is evaluated. Like the matrix $\underline{\mathrm{L}}\left(\mathbf{c}_{\mathrm{K}}\right)$, the vector $\mathbf{w}\left(\mathbf{c}_{\mathrm{K}}\right)$ is known.

Defintion (A 5. 10) does not define a unique Riemann invariant. The following theorem gives us a convenient choice.

Theorem: The scalar product of the left eigenvector and the concentration vector c evaluated at the k-th constant state

$\mathrm{w}_{\mathrm{j}}\left(\mathbf{c}_{\mathrm{k}}\right)=\mathbf{l}_{\mathrm{j}}\left(\mathbf{c}_{\mathrm{k}}\right) \mathbf{c}_{\mathrm{k}}, \quad\left(\mathrm{j}, \mathrm{k}=1,2, \ldots, \mathrm{N}_{0}, \mathrm{j} \neq \mathrm{k}\right)$

is a k-Riemann invariant.

\section{Proof:}

$\mathbf{r}_{\mathrm{k}} \nabla_{\mathrm{c}} \mathrm{W}_{\mathrm{j}}=\mathbf{r}_{\mathrm{k}}\left(\nabla_{\mathrm{c}} \mathbf{l}_{\mathrm{j}} \mathbf{c}+\mathbf{l}_{\mathrm{j}} \nabla_{\mathrm{c}} \mathbf{c}\right)=\mathbf{r}_{\mathrm{k}} \nabla_{\mathrm{c}} \mathbf{l}_{\mathrm{j}} \mathbf{c}+\mathbf{r}_{\mathrm{k}} \mathbf{l}_{\mathrm{j}}, \quad(\mathrm{j} \neq \mathrm{k})$. 
Because of (A 5. 8) $\mathbf{r}_{k} \nabla_{c} \mathbf{l}_{j}$ in the first term of (A 5. 13), the derivative of $\mathbf{l}_{\mathbf{j}}$ in direction of $\mathbf{r}_{\mathrm{k}}$, is zero:

$\mathbf{r}_{\mathrm{k}} \nabla_{\mathrm{c}} \mathbf{l}_{\mathrm{j}}=0, \quad(\mathrm{j} \neq \mathrm{k})$.

By (A 5. 4) the last term in (A 5. 13) is zero. Thus,

$\mathbf{r}_{\mathrm{k}} \nabla_{\mathrm{cW}}=0 \quad(\mathrm{j} \neq \mathrm{k})$,

which is the definition of the k- Riemann invariant, q.e.d.

The solution of the Riemann problem is now straighforward. Equation (A 5. 12) can be written in matrix form

$\mathbf{w}\left(\mathbf{c}_{\mathrm{k}}\right)=\underline{\mathrm{L}}\left(\mathbf{c}_{\mathrm{k}}\right) \mathbf{c}_{\mathrm{k}}$

where $\mathbf{w}\left(\mathbf{c}_{\mathrm{k}}\right)$ and $\underline{\mathrm{L}}\left(\mathbf{c}_{\mathrm{k}}\right)$ are known for all $\mathbf{c}_{\mathrm{k}}$. Vector $\mathbf{c}_{\mathrm{k}}$ is the unknown. Inverting (A 5. 15)

$\underline{\mathrm{L}}^{-1}\left(\mathbf{c}_{\mathrm{k}}\right) \mathbf{w}\left(\mathbf{c}_{\mathrm{k}}\right)=\mathbf{c}_{\mathrm{k}}$

gives the solution of the Riemann problem.

\section{Notation}

First parentheses give units. (-) means dimensionless. Last parentheses give location where symbol is defined or first used.

$\alpha \quad$ index specifying site type, (64).

$\alpha_{\mathrm{iN}} \quad$ constant for $\mathrm{A}_{\mathrm{j}}-\mathrm{A}_{\mathrm{N}}$ exchange, (-), (37).

c vector of soluble concentration $\left\{\mathrm{M}, \mathrm{H}_{\mathrm{t}}\right\},(6)$.

$c_{j}(x, t) \quad$ soluble concentration of component $A_{j}$, (mol per Liter of liquid), (1). Index $\mathrm{j}$ is omitted in 1component system, (A 1.1). 
$\mathbf{c}_{\mathrm{k}}$

vector of soluble concentrations in constant state between $\mathrm{k}$ - and (k+1)-wave, (figure 1), (A 5. 1).

$\mathbf{c}_{\infty}(\mathrm{x}, \mathrm{t})$ time asymptotic soluble concentration profile, (mol per Liter of liquid), (A 1. 3).

$\mathbf{c}_{+} \quad$ soluble concentration vector right of conentration jump at $t=0$, (mol per Liter of liquid), (4). Scalar $\mathrm{c}_{+}$is used for the 1-component system (A 1. 6).

c soluble concentration vector left of conentration jump at $\mathrm{t}=0$, (mol per Liter of liquid), (4). Scalar $\mathrm{c}_{-}$is used for the 1-component system (A 1. 6).

composition

space

space the axes of which are the concentrations $\mathrm{M}$ and $\mathrm{H}$ (Figure 3).

$\mathrm{C}_{\mathrm{j}}(\mathrm{x}, \mathrm{t}) \quad$ concentration of component $\mathrm{A}_{\mathrm{j}}$ on the surface, (mol per Liter of system volume), (2). Index $\mathrm{j}$ is omitted in 1-component system, (A 1.1).

$\mathrm{C}_{\mathrm{j}}{ }^{*}(\mathbf{c}) \quad$ equilibrium concentration of component $\mathrm{A}_{\mathrm{j}}$ on the surface, (mol per Liter of system volume), (2), except in eqs. (37) - (99), where $C_{\mathbf{j}} *(\mathbf{c})$ means the concentration of a particular surface species. Concentration of component $A_{j}$ on surface is sum of the concentrations of the surface species containing $A_{j}$. Index $j$ is omitted in 1component system, (A 1.2).

D lumped hydrodynamic dispersion/molecular diffusion coefficient, $\left(\mathrm{m}^{2} / \mathrm{yr}\right),(1)$.

D* coefficient of molecular diffusion in water $(0.16$ $\mathrm{m}^{2} / \mathrm{yr}$ ), (A 1. 10).

$\delta \quad$ dispersivity, $(\mathrm{m}), \delta \approx \mathrm{L} / 100,($ A 1.10 ).

$\delta^{\alpha}(\mathbf{c}) \quad$ measure of sum of concentrations adsorbed on site type $\alpha,(-),(64)$. $\alpha$ is omitted if there is only one site type, (101), (A 3. 3). 
$\nabla_{\mathrm{c}}$

$\varepsilon_{\mathrm{j}}$

$\mathbf{h}(\xi)$

$\mathrm{h}_{\mathrm{j}}(\xi)$

$\mathbf{H}(\xi)$

$\underline{\mathrm{H}}(\mathrm{M}, \mathrm{H}) \quad$ adsorbed proton concentration, (mol per Liter of system volume), (73).

$\mathrm{H}_{\mathrm{j}}(\xi) \quad$ component $\mathrm{j}$ of $\mathbf{H}(\xi), \mathrm{H}_{\mathrm{j}}(\xi)$ is adsorbed concentration $\mathrm{C}^{*}{ }_{\mathrm{j}}(\mathrm{x}, \mathrm{t})$ of component $\mathrm{A}_{\mathrm{j}}$ as a function of the speed $\xi=x / t$ of the concentration, (mol per Liter of system volume), (7) and (8).

$\mathrm{H}_{\mathrm{t}}(\xi) \quad$ total proton concentration in solution as a function of the speed $\xi=x / t$, (mol per Liter of liquid), (87).

$\mathrm{H}_{+} \quad$ proton activity in pre-equilibrant (pore water before arrival of abrupt concentration change, see (4)). $H_{+}=H(x \geq 0, t=0)$, (mol per Liter of liquid), (85).

$\mathrm{H}_{-} \quad$ proton activity in feed (see (4)), $\mathrm{H}_{-}=\mathrm{H}(\mathrm{x}<0, \mathrm{t}$ $=0)$, (mol per Liter of liquid), (88).

$\mathrm{H}_{\mathrm{t}-} \quad \mathrm{H}_{\mathrm{t}}(\mathrm{x}<0, \mathrm{t}=0),(86),($ mol per Liter of liquid).

HFO concentration of hydrous ferric oxide, $\mathrm{Fe}_{2} \mathrm{O}_{3}$, (mol per liter of system volume), (A 2. 38).

$\mathrm{j} \quad$ index specifying chemical component $A_{j},(-)$, (1). 
ionic strength, (mol/L), paragraph after (56).

I

identity matrix, (29).

$\mathrm{k}$

index specifying wave, the slowest wave has $\mathrm{k}=$ 1, (figure 1, (13).

$\mathrm{k} \quad$ threshold concentration of remobilizing component for accumulation of contaminant, (mol per Liter of liquid), (96) and (98).

$\mathrm{k}$ 1-component Langmuir adsorption constant, $(\mathrm{mol} / \mathrm{L})^{-1}$, (A 2. 21).

$\mathrm{k}_{1} \quad$ equilibrium constant for formation of $\mathrm{XOH}_{2}$ surface complex from $\mathrm{XOH}$ and $\mathrm{H},(\mathrm{L} / \mathrm{mol}),(49)$.

$\mathrm{k}_{2} \quad$ equilibrium constant for formation of $\mathrm{XO}$ surface complex from $\mathrm{XOH}$ and $\mathrm{H},(\mathrm{mol} / \mathrm{L}),(50)$.

$\underline{\mathrm{Kd}}(\mathbf{c}) \quad$ Jacobi matrix of isotherms evaluated at location c in composition space, (-), (29).

$\mathrm{K}_{\mathrm{W}} \quad$ water dissociation constant, $\left(10^{-14} \mathrm{~mol}^{2} / \mathrm{L}^{2}\right)$, (87).

$l_{k}(\mathbf{c}) \quad$ left eigenvector of $\underline{R}(\mathbf{c})$ corresponding to eigenvalue $\rho_{\mathrm{k}}(\mathbf{c}),(68)$.

L length of column of porous medium, (m), (paragraph after (1) and figure A 1).

$\underline{L}(\mathbf{c}) \quad$ matrix of left eigenvectors $1_{k}(\mathbf{c}),(69)$.

$\mathrm{M}(\xi) \quad$ soluble concentration of metal, (mol per Liter of liquid), (77).

$\underline{\mathrm{M}}(\mathrm{M}, \mathrm{H})$ adsorbed metal concentration, (mol per Liter of system volume), (74).

$\mathrm{M}_{+} \quad \mathrm{M}(\mathrm{x} \geq 0, \mathrm{t}=0),(83)$.

M. $\quad \mathrm{M}(\mathrm{x}<0, \mathrm{t}=0),(86)$. 


\begin{tabular}{|c|c|}
\hline $\mathrm{N}_{0}$ & number of chemical components, (-), (1). \\
\hline $\mathrm{P}$ & electrostatic correction factor, (-), (42) and (57). \\
\hline PZC & $\begin{array}{l}\text { point of zero charge on hydrous ferric oxide in } \\
\text { pristine water, i.e. at } \mathrm{I} \leq 0.0001 \mathrm{~mol} / \mathrm{L},(57) \text {. }\end{array}$ \\
\hline$\phi$ & porosity of medium, $(-),(1)$. \\
\hline $\mathbf{r}(\mathbf{h})$ & right eigenvector of $\underline{\mathrm{R}}$ evaluated at $\mathbf{c}=\mathbf{h},(33)$. \\
\hline $\mathbf{r}_{\mathrm{k}}(\mathbf{c})$ & $\begin{array}{l}\text { right eigenvector of } \underline{R}(\mathbf{c}) \text { corresponding to } \\
\text { eigenvalue } \rho_{\mathrm{k}}(\mathbf{c}),(33) \text {. }\end{array}$ \\
\hline$\underline{\mathrm{R}}(\mathbf{c})$ & $\begin{array}{l}\text { retardation matrix evaluated at location } \mathbf{c} \text { in con- } \\
\text { centration space, }(30) \text {. The matrix degenerates to } \\
\text { the retardation of the traveling wave, } R(c) \text {, in the } \\
\text { 1-component system, }(A 1.6) \text {. }\end{array}$ \\
\hline $\mathrm{R}_{\mathrm{k}}(\mathbf{c})$ & $\begin{array}{l}\text { retardation of k-rarefaction wave, }(-),(23) \text { and k- } \\
\text { shock, }(24) \text {. } R_{k} \text { of k-rarefaction wave is equal to } \\
\text { the kth eigenvalue } \rho_{k} \text { of } \underline{r} \text {, but } \underline{R}_{k} \text { of k-shock is } \\
\text { kth root of Rankine-Hugoniot relation }(24) \text { or } \\
(26) \text {. }\end{array}$ \\
\hline$\rho(\mathbf{c})$ & $\begin{array}{l}\text { eigenvalue of } \underline{R}(\mathbf{c}) \text {, also called "retardation", (-), } \\
\text { (32). }\end{array}$ \\
\hline$\rho_{\mathrm{k}}(\mathbf{c})$ & retardation of k-rarefaction wave, $(-),(34)$. \\
\hline $\mathrm{s}$ & $\mathrm{x}-\sigma \mathrm{t},(\mathrm{m}),(\mathrm{A} 1.4)$ \\
\hline$\sigma$ & speed of traveling wave, (m/yr), (A 1. 5). \\
\hline$\sigma_{\mathrm{k}}$ & speed of k-shock, (m/yr), (24). \\
\hline $\mathrm{t}$ & time variable, $(\mathrm{yr}),(1)$ \\
\hline$\tau$ & tortuosity, (-), (A 1. 10). \\
\hline $\mathrm{V}_{\mathrm{W}}$ & flux of water, (m/yr), (1). \\
\hline & speed of water, (m/yr), (A 2. 38). \\
\hline
\end{tabular}




\begin{tabular}{|c|c|}
\hline $\mathrm{w}_{\mathrm{j}}\left(\mathbf{c}_{\mathrm{k}}\right)$ & $\begin{array}{l}\text { k-Riemann invariant evaluated at } \mathbf{c}_{\mathrm{k}},(-),(65) \text { and } \\
(67) \text {. }\end{array}$ \\
\hline $\mathbf{w}\left(\mathbf{c}_{\mathrm{k}}\right)$ & $\begin{array}{l}\text { vector of } \mathrm{N}_{0} \text { Riemann invariants evaluated at } \mathbf{c}_{\mathrm{k}} \text {, } \\
(-),(70) \text {. }\end{array}$ \\
\hline $\mathrm{x}$ & spatial variable $(\mathrm{m}),(1)$ \\
\hline $\mathrm{X}_{\mathrm{T}}^{\alpha}$ & $\begin{array}{l}\text { concentration of adsorption sites of type } \alpha \text {, (mol } \\
\text { per Liter of system volume), (64). Index } \alpha \text { is } \\
\text { omitted when there is only one site type, (39). }\end{array}$ \\
\hline $\mathrm{XO}$ & $\begin{array}{l}\text { concentration of empty sites, (mol per Liter of } \\
\text { system), (50). }\end{array}$ \\
\hline $\mathrm{XOH}$ & $\begin{array}{l}\text { concentration of sites covered with one proton, } \\
\text { (mol per Liter of system), (49). }\end{array}$ \\
\hline $\mathrm{XOH}_{2}$ & $\begin{array}{l}\text { concentration of sites covered with two protons, } \\
\text { (mol per Liter of system), (49). }\end{array}$ \\
\hline XOHM & $\begin{array}{l}\text { concentration of sites covered with } \mathrm{M} \text { via a } \\
\text { proton bridge, (mol per Liter of system), ( } 44) \\
\text { and }(59) \text {. }\end{array}$ \\
\hline $\mathrm{XOM}$ & $\begin{array}{l}\text { concentration of sites covered with metal, (mol } \\
\text { per Liter of system), ( } 51) \text {. }\end{array}$ \\
\hline$\xi$ & speed of concentration $\mathbf{c},(\mathrm{m} / \mathrm{yr}),(5)$ \\
\hline 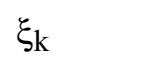 & speed of k-rarefaction wave, $(\mathrm{m} / \mathrm{yr}),(13)$. \\
\hline
\end{tabular}

\section{References}

Bear J (1979) Hydraulics of Groundwater. McGraw Hill Book Company, New York

Berninger JA, Whitley RD, Zhang X and Wang N-H L (1991) A versatile model for simulation of reaction and nonequilibrium dynamics in multicomponent fixed-bed adsorption processes. Computers Chem Engng 15(11): 749-768 
Bryant, SL, Dawson C, and van Duijn C (2000) Dispersion-induced chromatographic waves, Ind. Eng. Chem. Res., 39, 2682-2691

Charbeneau RJ (1981) Groundwater contaminant transport with adsorption and ion exchange chemistry: Method of characteristics for the case without dispersion, Water Resour. Res., 17, 705-713

Charbeneau RJ (1988) Multicomponent exchange and subsurface solute transport: characteristics, coherence, and the Riemann problem. Water Resour Res 24: 57-64

Cederberg GA, Street RL, and Leckie JO (1985) A groundwater mass transport and equilibrium chemistry model for multicomponent systems. Water Resour Res 21: 1095-1104

Dzombak DA and Morel FMM (1990) Surface Complexation Modeling: Hydrous Ferric Oxide. John Wiley, New York

Gruber J (2014) Oberflächenspeziationsprogramme vermitteln uns kein grundlegendes Verständnis der Adsorptionsvorgänge http://acamedia.info/sciences/J_G/sichtF/surf_cx.htm

Harwell J (1992) Fate of organic pollutants in immiscible non-aqueous solvents, in: D Petruzzelli and FG Helfferich (eds) Migration and Fate of Pollutants in Soils and Subsoils. Proceedings of the NATOAdvanced Study Institute Summer School, Aquafredda di Maratea, Italy, May 24 - June 6

Helfferich F (1967) Multicomponent ion-exchange in fixed beds, Ind Eng Chem Fundam 6: 362-364

Helfferich FG (1992) Multicomponent wave propagation: the coherence principle, in: D Petruzzelli and FG Helfferich (eds) Migration and Fate of Pollutants in Soils and Subsoils. Proceedings of the NATO-Advanced Study Institute Summer School, Aquafredda di Maratea, Italy, May 24 - June 6

Helfferich FG and Bennett BJ (1984) Weak electrolytes, polybasic acids, and buffers in anion exchange columns: I Sodium acetate and sodium carbonate systems. Reactive Polymers 3: 51 - 66 , II Sodium acetate chloride system, Solvent Extraction and Ion Exchange 2: 1151 $-1184$

Helfferich F and Klein G (1970) Multicomponent Chromatography Theory of Interference. Marcel Dekker, New York 
Hunt JR, Sitar N, and Udell KS (1988) Nonaqueous phase liquid transport and cleanup, 1 Analysis of mechanisms. Water Resour Res 24: $1247-1258$

Hwang Y-L, Helfferich FG, and Leu R-J (1988) Multicomponent equilibrium theory for ion-exchange columns involving reactions. AIChE J 34: 1615-1626

International AVS Center, North Carolina Supercomputing Center, PO Box 12889, 3021 Cornwallis Road, Research Triangle Park, North Carolina, NC 27709, telnet: avsncscorg

Kinzelbach W, Schäfer W, and Herzer J (1989) Numerical modeling of nitrate transport in a natural aquifer. in: $\mathrm{H}$ Kobus and W Kinzelbach (eds) Contaminant Transport in Groundwater. Balkema, Rotterdam, pp 191-198

Kirkner DJ and Reeves H (1988) Multicomponent mass transport with homogeneous and heterogeneous chemical reactions: the effect of the chemistry on the choice of numerical algorithm Part 1: theory. Water Resour Res 24: 1719-1729

Lake LW, and Helfferich F (1978) Cation exchange in chemical flooding, 2: The effect of dispersion, cation exchange, and polymer/surfactant adsorption on chemical flood environment. Soc Pet Eng J 18: 435-444

Lax PD (1957) Hyperbolic Systems of Conservation Laws II, Comm Pure Appl Math 10: 537 - 566

Lax PD (1973) Hyperbolic Systems of Conservation Laws and the Mathematical Theory of Shock Waves. Society of Industrial and Applied Mathematics, Philadelphia, PA 19103

Lichtner PC (1992) Time-space continuum description of fluid/rock interaction in permeable media. Water Resour Res 28: 3135-3155

Liu T-P (1987) Hyperbolic Conservation Laws with Relaxation. Commun Math Phys 108: 153-175

Lützenkirchen J (2012) Summary of studies on (ad)sorption as a "well-established" process within FUNMIG activities. Applied Geochemistry 27: 427-443 
http://www.deepdyve.com/lp/elsevier/summary-of-studies-on-adsorption-as-a-well-established-process-within-

P80JJ8F8uU?key=elsevier

Novak CF, Schechter, RS, and Lake LW (1988) Rule-based mineral sequences in geochemical flow processes. AIChE Journal 34: 16071614

Ortoleva P, Merino E, Moore G , and Chadam J (1987) Geochemical self-organization I: Reaction-transport feedbacks and modeling approach. Am J Sci 287: 979-1007

Payne TE et al. (2013) Guidelines for thermodynamic sorption modelling in the context of radioactive waste disposal, Environmental Modelling \& Software 42 (2013): 143-156

http://apo.ansto.gov.au/dspace/handle/10238/4574

Pfann W (1958) Zone Melting. John Wiley, New York

Prigiobbe V, Hesse MA, and Bryant SL (2012) Anomalous reactive transport in the framework of the theory of chromatography, Transp. Porous Med., 93, 127-145

Prigiobbe V, Hesse MA, and Bryant SL (2012) Fast strontium transport induced by hydrodynamic dispersion and $\mathrm{pH}$-dependent sorption, Geophys. Res. Lett., 39, L18401

Prigiobbe V, Hesse MA, and Bryant SL (2013) Hyperbolic theory for flow in permeable media with $\mathrm{pH}$-dependent adsorption, SIAM J. Appl. Math., 73, 1941-1957

Reeves H and Kirkner DJ (1988) Multicomponent mass transport with homogeneous and heterogeneous chemical reactions: the effect of the chemistry on the choice of numerical algorithm, part II: numerical results. Water Resour Res 24: 1730-1739

Rhee H-K, Aris R, and Amundson NR (1989) First-Order Partial Differential Equations: Volume II, Theory and Application of Hyperbolic Systems of Quasilinear Equations. Prentice Hall, Englewood Cliffs, NJ 07632

Schweich D, Sardin M, and Jauzein M (1993) Properties of Concentration Waves in Presence of Nonlinear Sorption, Precipitation/Dissolution, and Homogeneous Reactions, 1 Fundamentals, 2 Illustrative Examples. Water Resour Res 29: 723 - 741 
Stumm W and Morgan JJ (1981) Aquatic Chemistry (2nd ed). John Wiley

Temple B (1983) Systems of Conservation Laws with Invariant Submanifolds. Trans Amer Math Soc 2: 781 - 795

Vogt M (1990) Ein vektorrechnerorientiertes Verfahren zur Berechnung von großräumigen Multikomponenten-Transport-ReaktionsMechanismen im Grundwasserleiter. Dissertation, University of Karlsruhe, VDI Verlag

Walsh MP, Bryant SL, Schechter RS, and Lake LW (1984) Precipitation and dissolution of solids attending flow through porous media. AIChE J 30: 317-328

Wolfram Research Inc. (1992) Mathematica, Version 2.2, Wolfram Research Inc, 100 Trade Center Drive, Champaign, Illinois, IL 618207237, USA E-Mail: info@wricom

van der Zee SEATM (1990) Analytical traveling wave solution for transport with nonlinear nonequilibrium adsorption, Water Resour Res 26: 2563-2577

Zielke C (1993) Transport von spezifisch adsorbierenden Schwermetall-Kationen: Anwendung eines chromatographischen Modells zur Beschreibung und Interpretation von Fronten in binären Systemen. Diplomarbeit, Technische Universität Hamburg-Harburg, Arbeitsbereich Umweltschutztechnik 